\title{
TAp73 knockout shows genomic instability with infertility and tumor suppressor functions
}

\author{
Richard Tomasini, ${ }^{1,2,12}$ Katsuya Tsuchihara, ${ }^{1,3,12}$ Margareta Wilhelm, ${ }^{1}$ Masashi Fujitani, ${ }^{4}$ \\ Alessandro Rufini, ${ }^{1,5}$ Carol C. Cheung, ${ }^{1,6}$ Fatima Khan, ${ }^{7}$ Annick Itie-Youten, ${ }^{1}$ Andrew Wakeham, ${ }^{1}$ \\ Ming-sound Tsao, ${ }^{8}$ Juan L. Iovanna, ${ }^{2}$ Jeremy Squire, ${ }^{9}$ Igor Jurisica, ${ }^{10}$ David Kaplan, ${ }^{4}$ \\ Gerry Melino, ${ }^{5,11}$ Andrea Jurisicova, ${ }^{7}$ and Tak W. Mak ${ }^{1,13}$ \\ ${ }^{1}$ The Campbell Family Institute for Breast Cancer Research, Princess Margaret Hospital, Toronto, Ontario M5G 2C1, \\ Canada; ${ }^{2}$ Institut National de la Santé et de la Recherche Médicale Unité 624, Stress Cellulaire, 13288 Marseille Cedex 9, \\ France; ${ }^{3}$ Research Center for Innovative Oncology, National Cancer Center Hospital East, Kashiwa, Chiba 277-8577, Japan; \\ ${ }^{4}$ The Hospital for Sick Children MaRs Centre, Toronto Medical Discovery Tower, Toronto, Ontario M5G 1L7, Canada; \\ ${ }^{5}$ Biochemistry IDI-IRCCS Laboratory, c/o University of Rome "Tor Vergata," 00133 Rome, Italy; ${ }^{6}$ Department of Pathology, \\ University Health Network, University of Toronto, Toronto, Ontario M5G 2C4, Canada; ${ }^{7}$ Division of Reproductive \\ Endocrinology and Infertility, Department of Obstetrics and Gynecology, Mount Sinai Hospital, Toronto, Ontario M5G 2C1, \\ Canada; ${ }^{8}$ Division of Applied Molecular Oncology, Ontario Cancer Institute, Department of Medical Biophysics, University \\ of Toronto, Toronto, Ontario M5G 2C4, Canada; ${ }^{9}$ Department of Laboratory Medicine and Pathobiology, University of \\ Toronto, Toronto, Ontario M5G 1L5, Canada; ${ }^{10}$ Division of Signaling Biology, Ontario Cancer Institute, Department of \\ Medical Biophysics, University of Toronto, Toronto, Ontario M5G 2C4, Canada; ${ }^{11}$ Medical Research Council, Toxicology \\ Unit, Hodgkin Building, Leicester University, Leicester LE1 9HN, United Kingdom
}

The Trp53 gene family member Trp73 encodes two major groups of protein isoforms, TAp73 and $\Delta \mathrm{Np} 73$, with opposing pro- and anti-apoptotic functions; consequently, their relative ratio regulates cell fate. However, the precise roles of p73 isoforms in cellular events such as tumor initiation, embryonic development, and cell death remain unclear. To determine which aspects of p73 function are attributable to the TAp73 isoforms, we generated and characterized mice in which exons encoding the TAp73 isoforms were specifically deleted to create a TAp73-deficient $\left(\mathrm{TAp} 73^{-/-}\right.$) mouse. Here we show that mice specifically lacking in TAp73 isoforms develop a phenotype intermediate between the phenotypes of $\operatorname{Trp} 73^{-/-}$and $\operatorname{Trp} 53^{-/-}$mice with respect to incidence of spontaneous and carcinogen-induced tumors, infertility, and aging, as well as hippocampal dysgenesis. In addition, cells from TAp $73^{-/-}$mice exhibit genomic instability associated with enhanced aneuploidy, which may account for the increased incidence of spontaneous tumors observed in these mutants. Hence, TAp73 isoforms exert tumor-suppressive functions and indicate an emerging role for Trp73 in the maintenance of genomic stability.

[Keywords: p73; tumor-prone phenotype; meiosis; infertility; genomic instability]

Supplemental material is available at http://www.genesdev.org.

Received May 13, 2008; revised version accepted August 6, 2008.

p73 belongs to a small but important family of p53-related proteins (p53, p63, p73). These proteins, which are encoded by the Trp53, Trp63, and Trp73 genes, respectively, are all transcription factors involved in the regulation of development, cell death, proliferation, stem cell renewal, and cell fate commitment, as well as tumorigenesis (Yang et al. 2002; Vousden and Lane 2007). Like

\footnotetext{
${ }^{12}$ These authors contributed equally to this work.

${ }^{13}$ Corresponding author.

E-MAIL tmak@uhnres.utoronto.ca; FAX (416) 2045300.

Article published online ahead of print. Article and publication date are online at http://www.genesdev.org/cgi/doi/10.1101/gad.1695308. Freely available online through the Genes \& Development Open Access option.
}

p53, several different protein isoforms of p63 and p73 have been reported, whose functions may compete with, synergize with, or be unrelated to those of p53 (Bourdon et al. 2005; Li and Prives 2007).

The Trp73 gene, discovered in 1997 (Kaghad et al. 1997), contains two promoters that drive the expression of two major groups of p73 isoforms with opposing cellular actions: The TAp73 isoforms contain the p73 transactivation domain (TA) and exhibit proapoptotic activities (Müller et al. 2005; Wang et al. 2007), whereas the $\Delta \mathrm{Np} 73$ isoforms lacking the N-terminal TA domain are anti-apoptotic (Grob et al. 2001). Consequently, due to the complexity of the cross-talk between all p53 family 
members and the opposing functions of p73 isoforms harbored in the same gene, the specific role of Trp73 in various biological processes is still debated (McKeon and Melino 2007; Stiewe 2007).

Mouse gene targeting studies have revealed that both Trp63 and Trp73 are required for normal embryogenesis (Mills et al. 1999; Yang et al. 1999, 2000). In contrast, the majority of mice deficient in Trp53 are viable and appear normal, although $\sim 30 \%$ of p53-deficient females die in utero with neuronal defects (Donehower et al. 1992). In addition, Trp53 $53^{-/}$mice of both sexes are more susceptible than the wild type to the development of spontaneous tumors (Donehower et al. 1992). In comparison, studies of mice that are homozygous or heterozygous for a complete deletion of Trp73 have produced conflicting results. Indeed, while inactivation of all p73 isoforms in mice does not enhance susceptibility to spontaneous tumors (Yang et al. 2000), Trp73 haploinsufficiency contributes to an increased incidence of spontaneous tumors such as lung adenoma, lung adenocarcinoma, thymic lymphoma, squamous cell hyperplasia, or hemangiosarcoma, particularly when combined with Trp53 heterozygosity (Flores et al. 2005). However, this gene interaction appears to be tissue-specific as Trp73 does not contribute to Trp53 tumor suppressor activity during lymphomagenesis (Perez-Losada et al. 2005). It is likely that Trp $73^{-/-}$mouse models do not show enhanced spontaneous tumor formation be due to shortened life span. Despite the fact that studies involving $\operatorname{Tr} p 73^{+/-}$revealed enhanced tumor formation, the $\operatorname{Tr} p 73^{-/-}$mouse model does not seem to fully mirror the molecular changes seen in human cancers, where an altered ratio of TAp73/ $\Delta \mathrm{Np} 73$ isoforms is often present rather than a total loss or mutation of p73 isoforms (Coates 2006). Thus, despite the usefulness of $\operatorname{Trp} 73^{-1-}$ mice, isoform-selective knockouts of Trp73 are needed to truly evaluate p73's impact on tumorigenesis and other cellular processes.

The complexity of the overlapping, combined, and opposing functions of Trp53 family members and their protein isoforms suggests the existence of an intricate functional network (Deyoung and Ellisen 2007). Over the last few years, several studies have suggested specific roles for particular p73 isoforms (De Laurenzi et al. 1998; Murray-Zmijewski et al. 2006; Klanrit et al. 2008). Thus, these data indicate that the ratio of various p73 isoforms present in an individual cell determines the outcome of p73 function, rather than the sum of the activities of each isolated p73 isoform. To investigate this hypothesis and elucidate the biological role of TAp73 isoforms, we generated mice that are missing exons encoding the TA domain of p73 (TAp73-/- mice). These mutants are deficient only in TAp73 isoforms and remain capable of producing $\Delta \mathrm{Np} 73$ isoforms causing a great imbalance in the TAp $73 / \Delta N p 73$ ratio. We clearly demonstrate that TAp73 isoforms are tumor-suppressive, which may be a consequence of TAp73's apparent role in the maintenance of genomic stability. In addition, we demonstrate that TAp73 is a novel maternal-lethal gene whose deficiency in mice causes infertility, and its loss mimics Trp73 deficiency causing hypocampal dysgenesis.

\section{Results \\ Characterization of TAp73 deletion and its effects on the expression and activities of Trp53 family members}

To determine the specific role of the TAp73 isoforms of p73 (Fig. 1A), we generated TAp73-deficient mice in which deletion of exons 2 and 3 of the Trp 73 gene (Fig. 1B) selectively abolished expression of all TAp73 isoforms (Supplemental Fig. S1A-C). Firstly, we confirmed the specific deletion of TAp73, and we analyzed the expression patterns of $\Delta \mathrm{Np} 73, \mathrm{p} 53$, and $\mathrm{p} 63$ in various tissues of TAp $73^{-/-}$mice. Although p53 and p63 expression were not modified (Supplemental Fig. S2A,D; data not shown), $\Delta$ Np73 mRNA was up-regulated in most tissues of TAp $73^{-1-}$ mice (Fig. 1C; Supplemental Fig. S2B). The exception was the lung, where $\Delta$ Np 73 mRNA was not significantly different from that of wild-type mice (Fig. 1C). We also observed enhanced $\Delta$ Np73 mRNA expression in TAp $73^{-/-}$mouse embryonic fibroblasts (MEFs), and this increased expression was persistent even after the excision of the PGK-neo cassette (Supplemental Fig. S1D,E), indicating that the observed up-regulation of $\Delta$ Np73 mRNA is due to the absence of TAp73 proteins rather than to the insertion of the PGK-neo cassette close to the $\Delta \mathrm{Np} 73$ promoter. However, the enhanced $\Delta$ Np73 mRNA level is not reflected in a significant increase in $\Delta \mathrm{Np} 73$ protein level. Indeed, we analyzed $\Delta \mathrm{Np} 73$ protein level in lung and ovaries from TAp73-/tissues versus wild-type tissues by using two antibodies-one specific of the $\Delta \mathrm{N}$ region (IMG-313) and one specific of the a-C-terminal region from all p73 isoforms (C-17) - and we compared the bands corresponding to the $\Delta \mathrm{Np} 73$ isoforms (Fig. 1D). Therefore, the antibody data would suggest that the increases in $\Delta N p 73$ transcript levels are not accompanied by parallel increases in expression of $\Delta \mathrm{Np} 73$ protein. The elevated levels of $\Delta \mathrm{Np} 73$ mRNA in TAp $73^{-/-}$mice were unexpected because TAp73 is a known transcriptional inducer of $\Delta \mathrm{Np} 73$ (Grob et al. 2001). However, further examination showed that, in wild-type mice, $\Delta \mathrm{Np} 73$ levels decreased more rapidly than levels of TAp73 following DNA damage (Maisse et al. 2004; Toh et al. 2004) due to the ubiquitination and proteasomal degradation of $\Delta \mathrm{Np} 73$ by an asyet-uncharacterized ubiquitin ligase (B.S. Sayan, C. Piro, A.L. Yang, and G. Melino, unpubl.). These data suggest that there are multiple mechanisms that operate posttranscriptionally to control the levels of various p73 isoforms, resulting in a complex inteplay between TAp73 and $\Delta \mathrm{Np} 73$. Nonetheless, our TAp $73^{-/-}$knockout seems to be a pure TAp73-deficient mouse at the protein level,

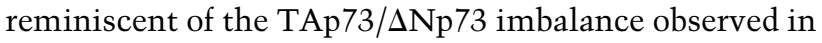
human tumors.

Since $\Delta \mathrm{Np} 73$ is a functional inhibitor of p53 and TAp73 isoforms (Grob et al. 2001; Deyoung and Ellisen 2007), and as we observed an increase in $\Delta$ Np73 mRNA level, we wanted to be sure that no $\Delta \mathrm{Np} 73$ activity was induced, potentially interfering with p53 functions. We showed that p53 activation was comparable in wild-type and TAp73 ${ }^{-/-}$MEFs (Supplemental Fig. S2C,D). Further- 
A

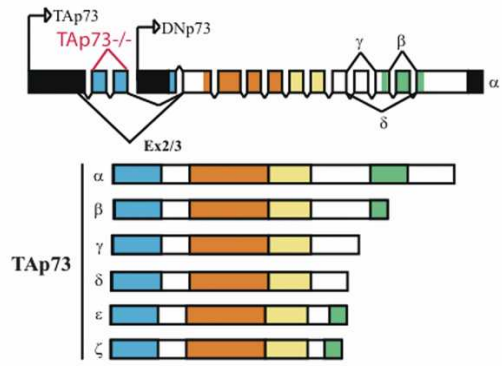

C

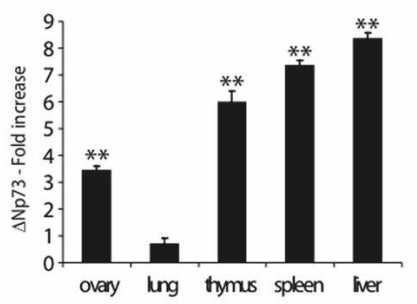

E

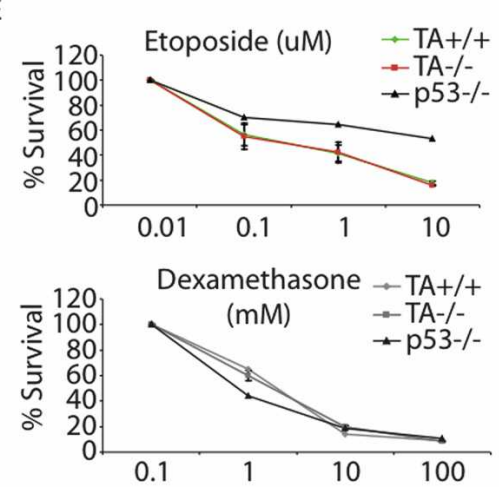

B

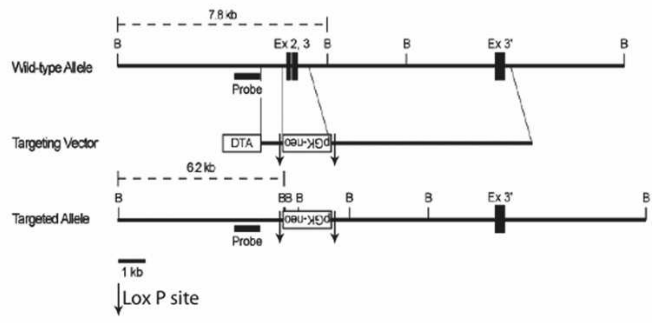

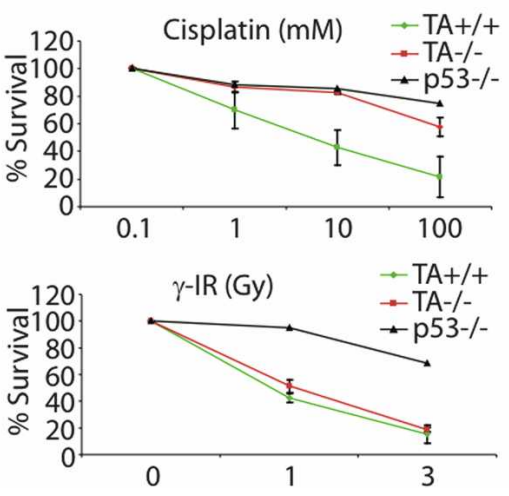

Figure 1. Generation of TAp73-/- mice and up-regulation of $\Delta \mathrm{Np} 73$ expression. $(A)$ Structure of the murine Trp73 gene showing the TAp73 and $\Delta$ Np73 isoform families. Domains: (blue) transactivation; (orange) DNA binding; (yellow) oligomerization; (green) sterile $\alpha$ motif. (B) Targeting strategy. Homologous recombination of the indicated targeting vector with the wild-type Trp73 gene resulted in the replacement of $\sim 1.5 \mathrm{~kb}$ with the neo gene and the deletion of exons 2 and 3 specific to the TAp73 isoform. LoxP sites and the probe used for Southern blotting are indicated. (C) Quantitation of $\Delta \mathrm{Np} 73$ expression in tissues from TAp $73^{+/+}$and TAp $73^{-/-}$mice. Fold increase of $\Delta \mathrm{Np} 73 \mathrm{mRNA}$ level in TAp $73^{-/-}$tissues compared with wild-type tissues by real-time PCR. $\left.{ }^{\star \star}\right) P<0.01$ (Student's $t$-test). $(D)$ Western blot analysis of $\Delta \mathrm{Np} 73$ level in lung and ovary from 10-mo-old wild-type and TAp73-deficient mice. C-17 antibody is specific from $\alpha$-C-terminal isoforms, and IMG-313 antibody is specific from $\Delta$ Np73 isoforms. (Ab) Antibody. (E) Thymocyte death. Thymocytes from TAp $73^{+/+}, \mathrm{TAp} 73^{-/-}$, and $\mathrm{p} 53^{-/-}$mice were treated for $24 \mathrm{~h}$ with the indicated agents at the indicated concentrations, and percent cell death was assayed by annexinV staining and flow cytometry. Data represent the mean \pm SD of two experiments.

more, we detected no differences between wild-type and $\mathrm{TAp}^{-1-}$ thymocytes (Fig. 1E), primary MEFs (Supplemental Fig. S2E), or E1A-transformed MEFs (Supplemental Fig. S2F) in p53-dependent cell death induced by $\gamma$-irradiation, etoposide, cisplatin, or doxorubicin. The normal sensitivity to death of TAp $73^{-/-}$thymocytes is particularly interesting in view of the finding that E2F binding to the TAp73 promoter is required for the TCR-induced death of human peripheral $\mathrm{T}$ cells from wild-type mice as well as for the death of cancer cells (Irwin et al. 2000; Lissy et al. 2000; Stiewe and Pützer 2000 ). Our data suggest that the $\triangle N p 73$ mRNA increase observed in most tissues from TAp73-deficient mice is not relevant since $\Delta \mathrm{Np} 73$ protein levels appear normal. A compensatory mechanism may have been elicited in the TAp73-deficient mice to guarantee normal $\Delta \mathrm{Np} 73$ protein expression under normal or physiological conditions. 
Loss of TAp73 leads to infertility due to defects in early embryonic development

A significant percentage of TAp $73^{-/-}$mice die during embryogenesis, resulting in an abnormal Mendelian ratio at birth $(+/+, 29 \% ;+/-, 52 \% ;-/-, 19 \%)$ either in mixed or pure background mice (Supplemental Fig. S3A). This partial embryonic lethality could theoretically be caused by the potential enhanced $\Delta \mathrm{Np} 73$ protein not balanced by the TAp73 at specific stages of embryonic development. Indeed, strongly deregulated $\Delta \mathrm{Np} 73$ expression in $\Delta \mathrm{Np} 73$ transgenic mice leads to $100 \%$ embryonic lethality partially due to inhibition of p53 activities (Erster et al. 2006; Huttinger-Kirchhof et al. 2006).

We were unable to obtain pups from mating trials involving mating a TAp $73^{-/-}$male or female with wildtype mice, suggesting that both sexes are infertile (Supplemental Fig. S3B). In contrast to Trp $73^{-/-}$mice, in which defects in sensory and hormonal pathways contribute to reproductive and behavioral phenotypes that lead to male and female infertility, TAp $73^{-/-}$mice mate normally and the females display normal cyclicity (Supplemental Fig. S3B; data not shown). To investigate the nature of TAp $73^{-/-}$female infertility, we induced superovulation in 3- to 4 -wk-old TAp $73^{-/-}$females and their wild-type littermate sisters using exogenous gonadotropins. In contrast to wild-type females, no oocytes were present in the fallopian tubes of TAp $73^{-/-}$females $16 \mathrm{~h}$ after administration of hCG (human choriogonadotropin). When the ovaries and oviducts of TAp $73^{-/-} \mathrm{fe}-$ males were dissected, we found that the ovulated oocytes were trapped under the bursa and did not progress toward the fallopian tubes (Fig. 2A, right). Upon collection of these oocytes, it became clear that TAp $73^{-/-}$females also ovulated fewer gametes (Fig. 2B).

To establish if altered follicular development was responsible for the oocyte deficit in TAp $73^{-/-}$female mice, we performed morphometric analyses (based on the counting of nonatretic follicles) of ovaries obtained from adolescent TAp $73^{+/+}$and TAp $73^{-/-}$females. Although significant differences were observed in the number of quiescent (primordial) or early growing (primary) follicles, numbers of early secondary follicles were comparable (Fig. 2C). To examine the later "Graffian follicle" stages, which are dependent on gonadotropins, we treated prepubertal TAp $73^{+/+}$and TAp $73^{-/-}$females with a single dose of pregnant mare serum gonadotropin (PMSG) to synchronize follicular development. Ovaries collected $46 \mathrm{~h}$ later revealed no significant differences in the competence of TAp $73^{-/-}$gonads to form large antral ovulatory follicles (Fig. 2D, left). However, when we assessed the ovulatory capacity of these follicles, we found that a greater number of oocytes remained trapped within the luteininzing granulosa cells of TAp $73^{-/-}$ovaries compared with wild-type females (Fig. $2 \mathrm{D}$, right). To confirm that $\Delta \mathrm{Np} 73$ was not responsible for that phenotype, we determined that $\Delta \mathrm{Np} 73$ mRNA expression level was even reduced in MII oocytes from TAp $73^{-/-}$mice compared with wild-type MII oocytes (Supplemental Fig. S4A). These results suggest that the decreased number of
Figure 2. Characterization of reproductive defects in TAp $73^{-/-}$female mice. $(A)$ Normal TAp $73^{-/-}$ovarian structure. (Left and center panels) Sections of ovaries from 4-wk-old $\mathrm{TAp} 73^{+/+}$and $\mathrm{TAp} 73^{-/-}$mice stained with picric acid and methyl blue. Magnification, $5 \times 10$. (Right panel) While no obvious differences in gross ovarian morphology were detected, ovulated oocytes were trapped under the bursa in TAp $73^{-/-}$ovary. Magnification, $40 \times 10$. (B) TAp73-deficient females ovulate fewer oocytes. Immature TAp $73^{+/+}$, TAp $73^{+/-}$, and $\mathrm{TAp} 73^{-/-}$females were superovulated, and the number of oocytes per mouse was counted. The results shown are the mean ovulated oocyte number \pm SE for the indicated number $(n)$ of mice/genotype. $\left(^{\star \star}\right)$ $P<0.001$ (Student's $t$-test). (C) Ovarian reserve is diminished by TAp73 deficiency. Serial sections of ovaries from superovulated immature $\mathrm{TAp} 73^{+/+}$and $\mathrm{TAp} 73^{-/-}$ mice were subjected to histomorphometric analysis. The results shown are the mean number of nonatretic follicles/mouse \pm SE for 5 mice per group. $\left.\left(^{\star}\right) P<0.01 ;{ }^{\star \star}\right) P<0.001$ (Student's $t$-test). The number of both primordial (Prd) and primary (Prm) follicles is significantly decreased, but the growth rate evidenced by the number of secondary follicles with two to three layers of granulosa cells $(\mathrm{Sec}-2 / 3)$ is not altered. $(D)$ The decreased number of ovulated oocytes is caused by impaired ovulation and not by insufficient follicular growth. The number of Graffian follicles with oocytes before (46 h/PMSG) and the number of luteinized follicles with oocytes after ovulation $(14 \mathrm{~h} / \mathrm{HCG})$ was determined in 3-wk-old TAp73 ${ }^{+/+}$and TAp73-/female mice. The results shown are the mean number of Graffian follicles/mouse \pm SE for $n=5$ mice per group. $\left({ }^{\star \star}\right) P<0.001$ (Student's $t$-test).
A
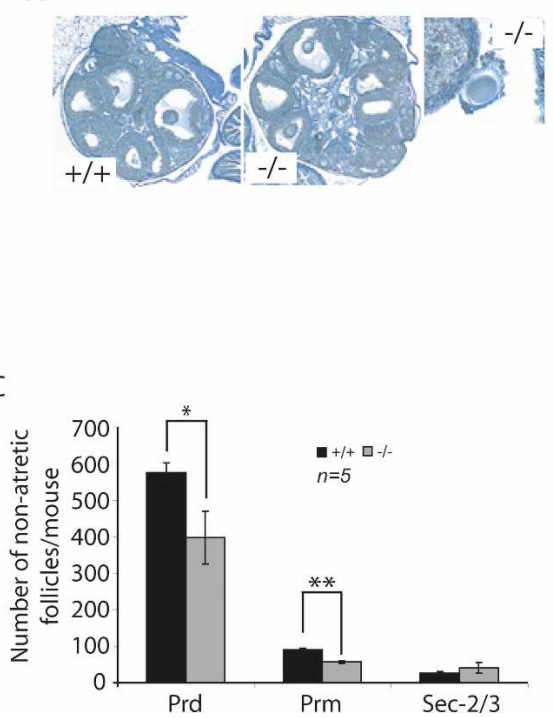

D

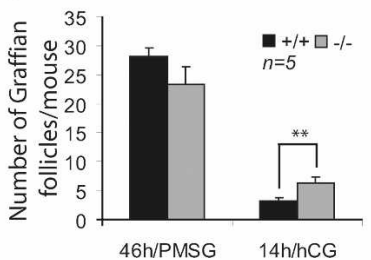


ovulated oocytes in TAp73-/- mice is likely due to the retention of some germ cells within the ovary.
We next investigated whether oocyte quality contributed to $\mathrm{TAp} 73^{-/-}$female sterility. Germinal vesicle oo-
A

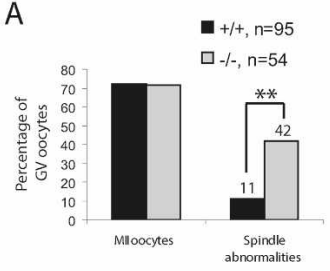

B

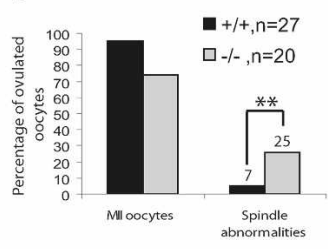

C

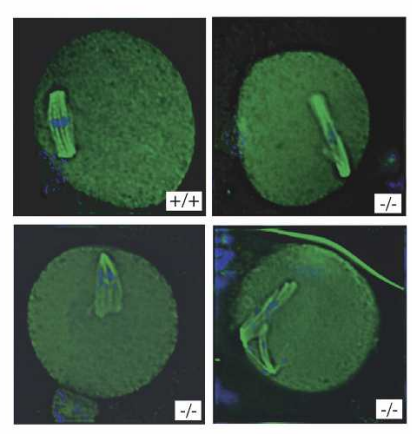

$\mathrm{F}$
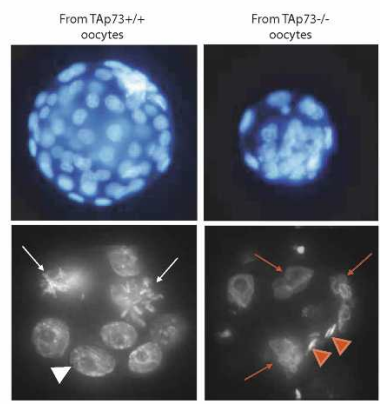

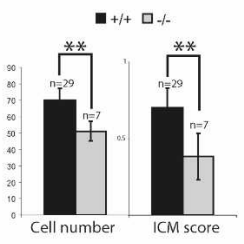

G

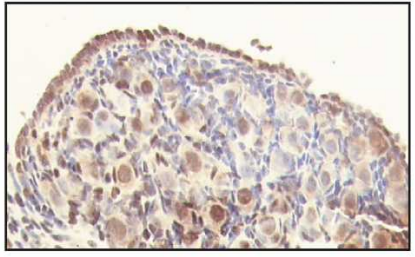

$\mathrm{H}$

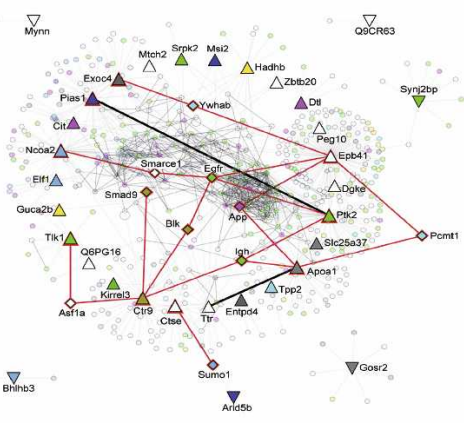

Figure 3. TAp73 deficiency effects on oocyte quality. $(A, B)$ Quantitation of spindle abnormalities in TAp $73^{+/+}$and TAp $73^{-/-}$oocytes matured in vitro $(A)$ or in vivo $(B)$. While no difference was observed in ability to proceed through the meiosis and arrest in metaphase II (MII), higher numbers of spindle abnormalities were detected in TAp73 oocytes. $\left.{ }^{\star \star}{ }^{\star}\right) P<0.001$ (Student's $t$-test). (C) Representative examples of $B$. Magnification, $40 \times 10$. $(D)$ The IVF procedure showed that no difference exists in the fertilization rate caused by TAp73 deficiency, but progression of zygotes through preimplantation development is abnormal. The percentage of TAp73-/- oocytes that upon fertilization reached the four- to eight-cell, morula, and blastocyst stages at appropriate developmental days is greatly diminished. $\left(^{\star}\right) P<0.01 ;\left(^{* \star *}\right) P<0.0001$. Statistical analyses were done using an $X 2$ test. (E) Poor quality of IVF-derived blastocysts obtained from TAp $73^{-/-}$oocytes as assessed by total cell number (left) and inner cell mass (ICM) score (right). ( $\left.^{\star *}\right) P<0.001$ (Student's $t$-test). (F) DAPI staining of blastocysts (top, magnification, $20 \times 10$ ) and eight-cell stage-arrested embryos (bottom, magnification, $40 \times 10)$ of $B$. (White arrows) Mitotic cells; (white arrowhead) normal nucleus; (red arrows) multinuclear cells; (red arrowheads) sperm heads. (G) TAp73 expression in a post-natal day $4 \mathrm{TAp} 73^{+/+}$ovary as detected by immunohistochemical staining with $\mathrm{H} 79$ antibody. (H) Network visualization of genes that were up-regulated in TAp $73^{+/+}$and TAp $73^{-/-}$neonatal ovaries. Node color represents GO (The Gene Ontology) function, as shown in the legend. Node shape represents different targets: Triangles pointed up are targets up-regulated in TAp $73^{-/-}$ovary; triangles pointing down are targets up-regulated in TAp $73^{+/+}$ovary. Diamonds and triangles outlined in red represent critical proteins within the network. Thicker lines indicate direct interactions among targets. Red lines represent critical interactions within the network. All other lines represent secondary interacting proteins. 
cytes as well as ovulated oocytes from 3- to 4-wk-old TAp $73^{+/+}$and TAp $73^{-/-}$mice were induced to mature in vitro. In both cases, oocytes of both genotypes showed the same rate of arrest in metaphase II (Fig. 3A,B, left). However, TAp $73^{-/-}$oocytes exhibited a striking increase in spindle abnormalities (Fig. 3A,B, right), which included multipolar spindles, spindle relaxation, and spindle scattering accompanied by varying degrees of misalignment (Fig. 3C). We next compared the developmental competence of ovulated TAp $73^{+/+}$and TAp $73^{-/-}$ oocytes by assessing their ability to undergo in vitro fertilization (IVF) and preimplantation development in vitro. While the fertilization rate was the same, only $28 \%$ of zygotes originating from $\mathrm{TAp} 73^{-/-}$oocytes became blastocysts, compared with $75 \%$ of zygotes originating from TAp $73^{+/+}$oocytes (Fig. 3D). The majority of embryos obtained from TAp $73^{-/-}$oocytes arrested during early cleavage, resulting in embryos with multinucleated blastomeres, and blastocysts of inferior quality with an abnormal cell number (Fig. 3E,F). Thus, Trp73 is a maternal-lethal effect gene, because a lack of TAp73 in developing oocytes leads to a failure of preimplantation embryonic development.

Poor oocyte quality leading to abnormal embryonic development is also associated with maternal aging, and is one of the most important prognostic factors of human infertility. Because oocytes from young TAp $73^{-/-}$mice displayed a similar spectrum of spindle abnormalities to that observed in oocytes from aged wild-type mice (Tarin et al. 2001), we evaluated TAp73 expression in the ovaries of 8 - and 55 -wk-old wild-type mice. We found that natural aging abolishes TAp73 expression in oocytes (Supplemental Fig. S4B,C). This observation suggests that loss of TAp73 may be responsible for the compromised developmental capacity of aged normal oocytes.

To identify TAp73 transcriptional targets potentially involved in the regulation of developmental competence, we decided to perform a gene microarray analysis of ovarian tissue. We first used immunocytochemistry to determine what stages of oogenesis were most likely to be affected by a lack of TAp73. Growing wild-type oocytes from the primary follicle stage onward displayed only cytoplasmic expression of TAp73, but the oocytes of wild-type primordial follicles often exhibited nuclear staining (Fig. 3G; Supplemental Fig. S4B). Thus, we used neonatal ovaries, which are enriched in oocytes at this developmental stage, as the target tissue for our microarray analysis. Our results showed that the expression of 79 annotated genes in neonatal ovary was altered by at least 1.8-fold by an absence of TAp73. We confirmed for some genes their modulation of expression in TAp $73^{-/-}$ ovaries compared with wild-type ovaries (Supplemental Fig. S5A,B; data not shown). Among these 79 genes, many were involved in the regulation of transcription and translation via control of RNA processing (see Tables 1,2). We confirmed that most of these genes are potential or already known p53 targets (Supplemental Fig. S5C). To determine functional links among the differentially regulated targets, we mapped them to the $\mathrm{I}^{2} \mathrm{D}$ protein interaction database (Brown and Jurisica 2007).
Extensive analyses identified several proteins that interacted strongly with TAp73, and also showed that all of these proteins were at points of network disconnect, which suggests that they are essential for signaling within this network (Fig. $3 \mathrm{H}$ ). Indeed, several of these genes (as example: PEG10 and Ctr9) have been disrupted in animal models with resulting embryonic lethality or infertility (Ono et al. 2006; Akanuma et al. 2007). Taken together, these data suggest that these target genes may normally be regulated by TAp73 or are physical interactors of TAp73, as, for example, in the case of PIAS1 that regulates cell cycle checkpoint progression by sumoylation of TAp73 (Munarriz et al. 2004), and thus their dysregulation may contribute to preimplantation lethality in the absence of TAp73.

\section{TAp73 is necessary for hippocampal development but not for neural cell maintenance}

Previous analyses of Trp $73^{-/-}$mice have demonstrated that p73 is critical for the development and maintenance of the nervous system (Yang et al. 2000). Indeed, Trp73-/mice exhibit hippocampal dysgenesis with a gradual but persistent postnatal loss of neurons with greatly enlarged ventricles (hydrocephalus) and greatly reduced cortical tissue (Yang et al. 2000; Pozniak et al. 2002). To investigate whether either of these phenotypes might be due to the loss of TAp73 isoforms, we carried out coronal sectioning of the brains of 10 -wk-old wild-type and TAp $73^{-1-}$ mice. Nissl staining of the forebrain revealed that TAp $73^{-/-}$brains were similar to their wild-type counterparts with regard to the size of the lateral ventricles and the thickness of the cortex (Fig. 4A,B) but that hippocampal anatomy was abnormal. In particular, the lower blade of the dentate gyrus was either completely missing or greatly truncated, depending on the level of the section (Fig. 4C-F). This hippocampal dysgenesis was strikingly similar to that seen in $\operatorname{Trp} 73^{-/-}$mice at postnatal day 14, before the occurrence of the ventricular enlargement and loss of neural tissue that further perturb hippocampal morphology in adult $\operatorname{Trp} 73^{-/-}$mice. The similarity between TAp $73^{-/-}$mice and $\mathrm{p} 73^{-/-}$mice on this particular phenotype suggests that it is due to TAp73 loss and not to $\Delta$ Np73 loss. Thus, our data support previous work (Pozniak et al. 2000, 2002; Walsh et al. 2004) showing that TAp73 is essential for normal hippocampal development, while $\Delta \mathrm{Np} 73$ seems to prevent neural tissue loss and ventricular enlargement in adult life.

\section{TAp $73^{-/-}$mice are tumor-prone and sensitive to carcinogens}

While infertility and neural abnormalities detected in the TAp $73^{-/-}$mice were not identical but reminiscent of those described for Trp $73^{-/-}$mice (Yang et al. 2000), other aspects of the phenotype were markedly different. Indeed, although the life span of TAp $73^{-/-}$mice was significantly shorter than that of wild-type mice (Fig. 5A), it 
Table 1. Target genes up-regulated in TAp73-/- ovary compared with wild-type ovary

\begin{tabular}{|c|c|c|c|}
\hline Gene ID & Fold change & Gene symbol & Gene title \\
\hline 1417761_at & 19.4 & Apoa4 & Apolipoprotein A-IV \\
\hline 1455201_x_at & 4.9 & Apoal & Apolipoprotein A-I \\
\hline 1458915_at & 3.4 & C77949 & Expressed sequence C77949 \\
\hline 1457705_at & 3.4 & 5330421C15Rik & RIKEN cDNA 5330421C15 gene \\
\hline 1439304_at & 3.3 & B230216N24Rik & RIKEN cDNA B230216N24 gene \\
\hline 1427550_at & 3.2 & Peg10 & Paternally expressed 10 \\
\hline 1453660_at & 3.0 & 5430420F09Rik & RIKEN cDNA 5430420F09 gene \\
\hline 1439594_at & 2.9 & D130062J10Rik & RIKEN cDNA D130062J10 gene \\
\hline 1420164_at & 2.9 & D7E $\operatorname{rtd} 183 \mathrm{e}$ & DNA segment, Chromosome 7, ERATO Doi 183, expressed \\
\hline 1433266_at & 2.9 & 2810416A17Rik & RIKEN cDNA 2810416A17 gene \\
\hline 1445881_at & 2.8 & 2310035P21Rik & RIKEN cDNA 2310035P21 gene \\
\hline 1442240_at & 2.7 & Ctr9 & Ctr9, Paf1/RNA polymerase II complex component \\
\hline 1433051_at & 2.6 & 2610011I18Rik & RIKEN cDNA $2610011 \mathrm{I} 18$ gene \\
\hline 1431402_at & 2.5 & Kirrel3 & Kin of IRRE like 3 (Drosophila) \\
\hline 1446258_at & 2.5 & 9530067D14Rik & RIKEN cDNA 9530067D14 gene \\
\hline 1430575_a_at & 2.4 & Tpp2 & Tripeptidyl peptidase II \\
\hline 1447051_at & 2.4 & Rnf43 & Ring finger protein 43 \\
\hline 1453753_at & 2.3 & Dtl & denticleless homolog (Drosophila) \\
\hline 1458097_at & 2.3 & Cobll1 & Cobl-like 1 \\
\hline 1453977_at & 2.3 & Exoc4 & Exocyst complex component 4 \\
\hline 1432665_at & 2.3 & 2210416J07Rik & RIKEN cDNA 2210416 J07 gene \\
\hline 1453361_at & 2.2 & Hells & Helicase, lymphoid-specific \\
\hline 1439128_at & 2.2 & Zbtb20 & Zinc finger and BTB domain containing 20 \\
\hline 1449573_at & 2.2 & Alpk3 & $\alpha$-Kinase 3 \\
\hline 1429870_at & 2.1 & Tnik & TRAF2 and NCK-interacting kinase \\
\hline 1446827_at & 2.1 & Ncoa2 & Nuclear receptor coactivator 2 \\
\hline 1442732_at & 2.1 & Hadhb & Hydroxyacyl-Coenzyme A dehydrogenase $\beta$ subunit \\
\hline 1439319_at & 2.1 & Elf1 & E74-like factor 1 \\
\hline 1458136_at & 2.1 & Msi2 & Musashi homolog 2 (Drosophila) \\
\hline 1438078_at & 2.1 & Dgke & Diacylglycerol kinase, $\varepsilon$ \\
\hline 1451580_a_at & 2.1 & Ttr & Transthyretin \\
\hline 1456407_a_at & 2.1 & LOC100046241, Tlk1 & tousled-like kinase 1 , similar to tousled-like kinase 1 \\
\hline 1453448_at & 2.1 & 2310067E 19Rik & RIKEN cDNA 2310067E 19 gene \\
\hline 1431525_at & 2.1 & 9130002K18Rik & RIKEN cDNA 9130002K18 gene \\
\hline 1460233_at & 2.1 & Guca2b & Guanylate cyclase activator $2 \mathrm{~b}$ (retina) \\
\hline 1430000_at & 2.1 & B230117O15Rik & RIKEN cDNA B230117O15 gene \\
\hline 1439095_at & 2.1 & Sfrs11 & Splicing factor, arginine/serine-rich 11 \\
\hline 1458737_at & 2.0 & C77097 & Expressed sequence C77097 \\
\hline 1458724_at & 2.0 & E 230008O15Rik & RIKEN cDNA E 230008015 gene \\
\hline 1427797_s_at & 2.0 & Ctse & Cathepsin E \\
\hline 1458807_at & 2.0 & Epb4.1 & Erythrocyte protein band 4.1 \\
\hline 1455040_s_at & 2.0 & 1110062M06Rik & RIKEN cDNA 1110062M06 gene \\
\hline 1432713_at & 2.0 & 6430709C05Rik & RIKEN cDNA 6430709C05 gene \\
\hline 1446265_at & 2.0 & Dnm3 & Dynamin 3 \\
\hline 1446448_at & 1.9 & Pias1 & Protein inhibitor of activated STAT 1 \\
\hline 1454299_at & 1.9 & 4833422B07Rik & RIKEN cDNA $4833422 B 07$ gene \\
\hline 1443384_at & 1.9 & Ptk2 & PTK2 protein tyrosine kinase 2 \\
\hline 1438842_at & 1.9 & LOC100039384, LOC & Mitochondrial carrier homolog 2 (Caenorhabditis elegans) \\
\hline 1431372_at & 1.9 & Srpk2 & Serine/arginine-rich protein specific kinase 2 \\
\hline 1451456_at & 1.9 & 6430706D22Rik & RIKEN cDNA 6430706D22 gene \\
\hline 1443121_at & 1.9 & Calcocol & Calcium binding and coiled-coil domain 1 \\
\hline 1455987_at & 1.9 & Sec61a1 & Sec61 $\alpha 1$ subunit (Saccharomyces cerevisiae) \\
\hline 1426028_a_at & 1.9 & Cit & Citron \\
\hline 1456166_at & 1.8 & Ehd2 & EH-domain containing 2 \\
\hline 1431761_at & 1.8 & Entpd4 & Ectonucleoside triphosphate diphosphohydrolase 4 \\
\hline 1454524_at & 1.8 & 2310075M01Rik & RIKEN cDNA 2310075M01 gene \\
\hline 1439363_at & 1.8 & 1200014J11Rik & RIKEN cDNA 1200014J11 gene \\
\hline 1444684_at & 1.8 & 8030475D13Rik & RIKEN cDNA 8030475D13 gene \\
\hline 1439213_at & 1.8 & Ston 1 & Stonin 1 \\
\hline 1451577_at & 1.8 & Zbtb20 & Zinc finger and BTB domain containing 20 \\
\hline
\end{tabular}


Table 2. Target genes down-regulated in TAp73-/- ovary compared with wild-type ovary

\begin{tabular}{lcll}
\hline Gene ID & Fold change & \multicolumn{1}{c}{ Gene symbol } & \multicolumn{1}{c}{ Gene title } \\
\hline 1436386_x_at & -2.8 & OTTMUS G 00000010671 & Predicted gene, OTTMUS G 00000010671 \\
1446469_at & -2.6 & E G 328,231 & Predicted gene, E G 328,231 \\
1419119_at & -2.1 & Hcst & Hematopoietic cell signal transducer \\
1438757_at & -2.1 & LOC 100,043,772 & Similar to crooked legs C G 14938-PB \\
1420792_at & -2.1 & 4930433N12Rik & RIKEN cDNA 4930433N12 gene \\
1428077_at & -2.0 & Tmem163 & Transmembrane protein 163 \\
1428985_at & -2.0 & Ints12 & Integrator complex subunit 12 \\
1429366_at & -1.9 & Lrrc34 & Leucine-rich repeat containing 34 \\
1421099_at & -1.9 & Bhlhb3 & Basic helix-loop-helix domain containing, class B3 \\
1452972_at & -1.9 & Ttc32 & Tetratricopeptide repeat domain 32 \\
1442176_at & -1.9 & Arid5b & AT-rich interactive domain 5B (Mrf1 like) \\
1429118_a_at & -1.9 & Zh2c2 & Zinc finger, H2C2 domain containing \\
1421333_a_at & -1.9 & Mynn & Myoneurin \\
1419372_at & -1.8 & Gosr2 & Golgi SNAP receptor complex member 2 \\
1457127_at & -1.8 & Defb42 & Defensin $\beta$ 42 \\
1450895_a_at & -1.8 & 1810020G 14Rik & RIKEN cDNA 1810020G 14 gene \\
\hline
\end{tabular}

still exceeded that of $\operatorname{Trp} 73^{-/-}$mice (Yang et al. 2000). Furthermore, whereas untreated $\operatorname{Trp} 73^{-1-}$ mice do not develop tumors, $30 \%$ of TAp $73^{+/-}$and $73 \%$ of TAp $73^{-/-}$ mice of a mixed genetic background spontaneously developed malignancies (Fig. 5B,C). Lung adenocarcinoma was the most frequent cancer that developed in TAp $73^{-/-}$mice, being observed in $32 \%$ of all TAp $73^{-/-}$ mice analyzed and representing $44 \%$ of all tumors excised from $\mathrm{TAp} 73^{-/-}$mice. In the lung of the $\mathrm{TAp} 73^{-/-}$ knockout, no changes in either $\Delta$ Np73 mRNA or protein compared with wild-type were observed (see above). Importantly, no correlation was found between tumor onset and p53, p63, or $\Delta \mathrm{Np} 73$ protein expression in any tumor analyzed (data not shown), suggesting that the appearance of tumors in TAp $73^{+/-}$and TAp $73^{-/-}$mice was specifically due to TAp73 deletion rather than to $\Delta \mathrm{Np} 73, \mathrm{p} 63$, or p53 deregulation. Consistent with a previous report (Roman-Gomez et al. 2006), loss-of-heterozygosity (LOH) of p73 had occurred in $66 \%$ of tumors developing in TAp $73^{+/-}$mice (Fig. 5D).

To confirm the tumor-prone phenotype of TAp $73^{-/-}$ mice, we induced carcinogenesis by intraperitoneal injection of DMBA into TAp $73^{+/+}$and TAp $73^{-/-}$female littermates. The mean latency time for tumor development in TAp $73^{-/-}$mice was $18.7 \pm 7.1 \mathrm{wk}$, significantly shorter than the $32 \pm 3.4$-wk mean latency observed in DMBA-treated TAp $73^{+/+}$mice (Fig. 5E). However, there was no difference between DMBA-treated TAp $73^{+/+}$and TAp $73^{-/-}$mice in sites of tumor development, which included the colon, intestine, liver, and stomach /data not shown). These results indicate that TAp73 isoforms mediate the tumor-suppressive function of $\operatorname{Trp} 73$, and that loss of TAp73 alone is sufficient to promote oncogenic transformation.

Taking into account the observation that TAp $73^{-/-}$ mice develop predominantly lung adenocarcinoma, we decided to investigate the expression of p73 isoforms in human lung cancer. Examination of the expression of TAp73 and $\Delta$ Np73 in matched normal and tumoral lung tissue samples from 18 lung cancer patients revealed that most tumoral lung samples exhibited a down-regulation of TAp73 and an up-regulation of $\Delta N p 73$, with a consequent decrease in the TAp $73 / \Delta N p 73$ ratio (Supplemental Fig. S6). Notably, in the two samples (patients 133 and 177) in which TAp73 expression was up-regulated, greater amounts of $\Delta \mathrm{Np} 73$ were also expressed. These results are consistent with the postulated inactivation of p53 in human lung cancer (Haruki et al. 2001).

\section{TAp73 participates in maintenance of genomic stability}

Since we observed an increased incidence of spontaneous tumors and also an abnormal spindle formation in the oocytes of TAp $73^{-/-}$mice, we next investigated the possible impact of TAp73 deficiency on the maintenance of genomic stability. Accurate chromosome segregation during meiosis and mitosis is critical to the preservation of euploidy in eukaryotic cells (Yuen et al. 2005), and errors in the molecular mechanisms regulating segregation result in aneuploidy (Hassold and Hunt 2001; Thomas et al. 2001). We analyzed the ability of TAp73deficient cells to undergo mitotic arrest and observed that TAp $73^{-/-}$MEFs showed a significant decrease in nocodozole-induced mitotic arrest. Indeed, at $25 \mathrm{~h}$ postnocodozole, the percentages of cells in $\mathrm{G} 1$ and $>\mathrm{G} 2 / \mathrm{M}$ were increased in TAp73-/- MEFs compared with TAp $73^{+/+}$MEFs (Fig. 6A; Supplemental Fig. S7A). Immunoblotting of mitotic phase marker proteins such as cyclin B1 and securin revealed that mitotic "slippage" had occurred in TAp73-/- MEFs (data not shown). Premature mitotic exit in TAp $73^{-/-}$MEFs was confirmed by immunostaining to detect phospho-histone H3-positive cells (Fig. 6B) and by counting mitotic figures (Fig. 6C, right). Thus, in the presence of nocodazole, TAp73 deficiency results in the abnormal mitotic progression of cells that otherwise would not be permitted to pass into the G1 phase. We observed a similar premature mitotic exit in p73 ${ }^{-1-}$ MEF cells treated with nocodazole, strongly suggesting that TAp73 isoforms are the functional isoforms 

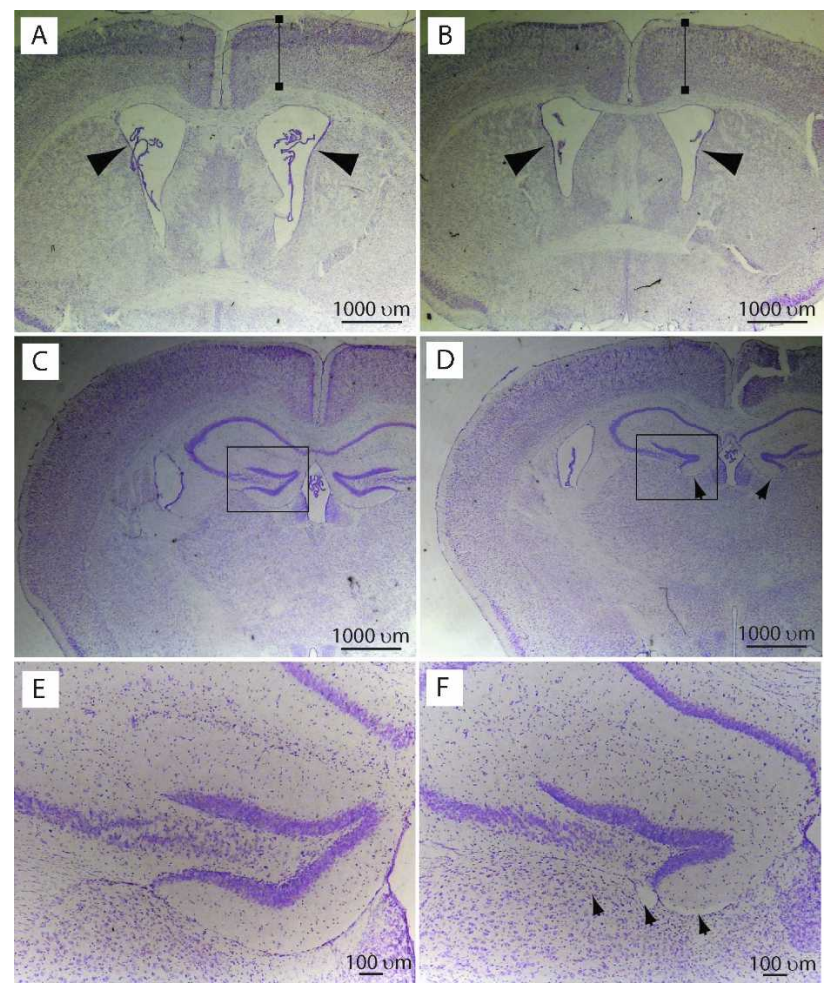

Figure 4. TAp73 is essential for normal hippocampal development. Representative pictures from multiple experiments using seven TAp $73^{+/+}$and seven TAp $73^{-/-}$mice of coronal forebrain sections of 4-mo-old TAp73 $3^{+/+}(A, C, E)$ and TAp73-/- $(B, D, F)$ C57B6 background mice stained with cresyl violet. $(A, B)$ Nisslstained coronal sections of forebrain at the level of the anterior commissure. Arrows indicate the lateral ventricles. Cortical thickness (brackets) was similar in $\mathrm{TAp} 73^{+/+}$and $\mathrm{TAp} 73^{-/-}$ brains. $(C-F)$ Nissl-stained coronal sections of the forebrain at the level of the rostral hippocampus. The area denoted by the boxes in $C$ and $D$ is shown at higher magnification in $E$ and $F$, respectively. Arrows in $D$ and $F$ denote the site of the lower blade of the dentate gyrus, which is missing in the TAp $73^{-/-}$ brain.

in mitotic regulation rather than $\Delta \mathrm{Np} 73$ isoforms (Supplemental Fig. S7B,C).

After $25 \mathrm{~h}$ of nocodazole treatment, an $8 \mathrm{~N}$ population of polyploid cells appeared frequently among TAp $73^{-/-}$ MEFs when compared with TAp73 $3^{+/+}$MEFs (Fig. 6A). Indeed, $\sim 14 \%$ of $\mathrm{TAp} 73^{-/}$MEFs showed aneuploidy compared with $5 \%$ of cells in TAp $73^{+/+}$MEF cultures. The percentage of multinuclear cells was also increased in TAp $73^{-1-}$ MEFs treated with taxol or nocodozole (Fig. 6C, left). When H1299 cells were engineered to overexpress the TAp $73 \beta$ isoform, they were protected from taxol-induced formation of multinuclear cells (Fig. 6D). In contrast, overexpression of $\Delta \mathrm{Np} 73 \alpha$ or $\Delta \mathrm{Np} 73 \beta$ in Trp $73^{-/-}$MEFs did not reduce the enhanced formation of multinuclear cells (data not shown).

We next examined lung and thymic cell populations from TAp $73^{-/}, \operatorname{Trp} 53^{-/-}$, and wild-type mice that were treated or not with nocodazole for $12 \mathrm{~h}$. TAp $73^{-/-}$lung fibroblasts showed a higher frequency of $>\mathrm{G} 2 / \mathrm{M}$ cells, demonstrating a loss of euploidy, which are likely aneuploid, than did Trp53-/- or wild-type lung fibroblasts, whereas no differences were observed among TAp $73^{-/-}$, Trp53/-, and wild-type thymic cells (Fig. 6E,F). Thus, the effect of TAp73 on aneuploidy appears to be tissuespecific, perhaps explaining why TAp $73^{-/-}$mice preferentially develop lung adenocarcinomas. Our results indicate that, at least in lung tissue, TAp73 loss is associated with decreased genomic stability.

To confirm more directly that TAp73 deficiency is associated with an altered DNA content, we karyotyped TAp $73^{-/-}$and TAp $73^{+/+} 3 \mathrm{~T} 3$ cells and observed that the mutant cultures contained a significantly higher percentage of cells with an abnormal karyotype compared with wild-type controls (Fig. 6G). The affected cells showed a loss or gain of a single chromosome, indicating aneuploidy. These data further support a role for TAp73 in maintaining genomic stability.

\section{Discussion}

As mentioned above, mouse models featuring deletion of all p73 isoforms (Yang et al. 2000), or p73 deletion in combination with Trp53 deficiency (Flores et al. 2005; Perez-Losada et al. 2005), or overexpression of specific p73 isoforms (Huttinger-Kirchhof et al. 2006), have all been helpful in dissecting the role of $\operatorname{Trp} 73$ in various biological processes. However, these mouse models cannot distinguish between the effects of the TAp73 and $\Delta \mathrm{Np} 73$ isoforms, so that the relative importance of these isoforms in specific biological processes remains unclear or even conflicting. In our study, we generated and analyzed the effects of a selective deficiency of TAp73 isoforms. Our comparison of the phenotypes of $\operatorname{Trp} 73^{-/-}$ and TAp $73^{-/-}$mice has clearly identified several functions that require TAp73 as opposed to $\Delta \mathrm{Np} 73$. However, single isoform deletion models, the complete deletion of all isoforms, and even partial deletions and hypomorphic models will all be needed to completely understand the complex functional network mediated by p53 family members.

Both $\operatorname{Trp} 73^{-/-}$and $\mathrm{TAp} 73^{-/-}$mice are infertile, but the root causes of this infertility differ. $\operatorname{Tr} p 73^{-/-}$mice have sensory defects that prevent them from mating normally (Yang et al. 2000). In contrast, TAp $73^{-/-}$female mice mate normally but have oocytes of reduced developmental competence that result in impaired early embryogenesis. The increased frequency of spindle defects in TAp $73^{-/-}$ovulated oocytes may also contribute to the sterility of $\mathrm{TAp} 73^{-/-}$females, in line with the strong correlation of this parameter with human infertility (Baird et al. 2005). Importantly, our work has identified $\operatorname{Trp} 73$ as one of a handful of genes whose mutation generates a maternal lethal effect phenotype. Genes belonging to this group are required for the transition from maternal to embryonic control over embryogenesis. Accordingly, the spectrum of cellular defects observed in embryos originating from $\mathrm{TAp} 73^{-/-}$oocytes is remarkably similar to the range of embryonic defects observed in infertile patients undergoing IVF, particularly older patients (Har- 
Tomasini et al.

A

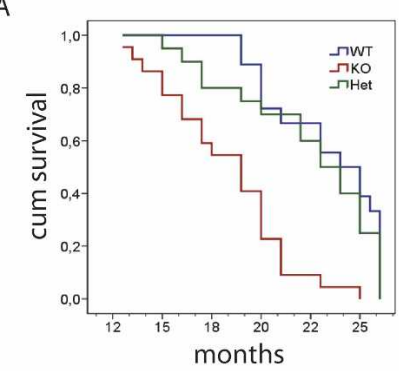

B

\begin{tabular}{lcll}
\hline Tumor type & $+/+(\mathrm{n}=18)$ & $\begin{array}{c}\text { Genotype } \\
+/-(\mathrm{n}=20)\end{array}$ & $-/-(\mathrm{n}=22)$ \\
\hline Thymic lymphoma & $0 / 18(0 \%)$ & $1 / 20(5 \%)$ & $3 / 22(14 \%)$ \\
Lymphoma & $1 / 18(6 \%)$ & $2 / 20(10 \%)^{*}$ & $4 / 22(18 \%)^{*}$ \\
Lung adenocarcinoma & $0 / 18(0 \%)$ & $1 / 20(5 \%)$ & $7 / 22(32 \%)$ \\
Colon carcinoma-in-situ & $0 / 18(0 \%)$ & $1 / 20(5 \%)$ & $2 / 22(9 \%)$ \\
Hemangiosarcoma & $0 / 18(0 \%)$ & $1 / 20(5 \%)$ & $0 / 22(0 \%)$ \\
Total tumor number (\% of total) & $1 / 18(6 \%)$ & $6 / 20(30 \%)$ & $16 / 22(73 \%)$ \\
\hline
\end{tabular}

* all these mice have infiltrating lymphoma in more than one organ

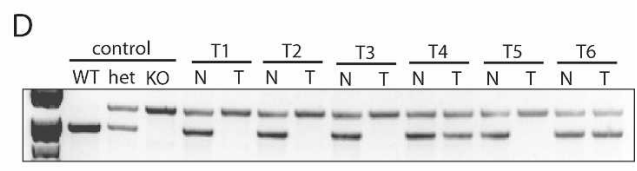

$\mathrm{E}$

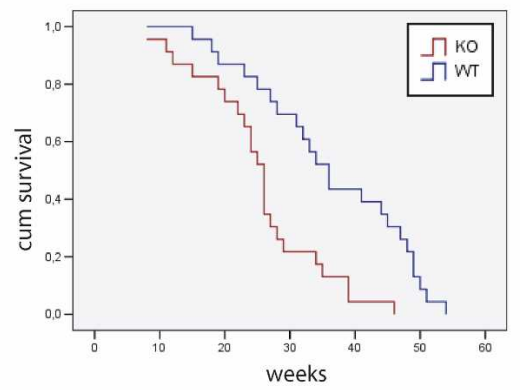

C
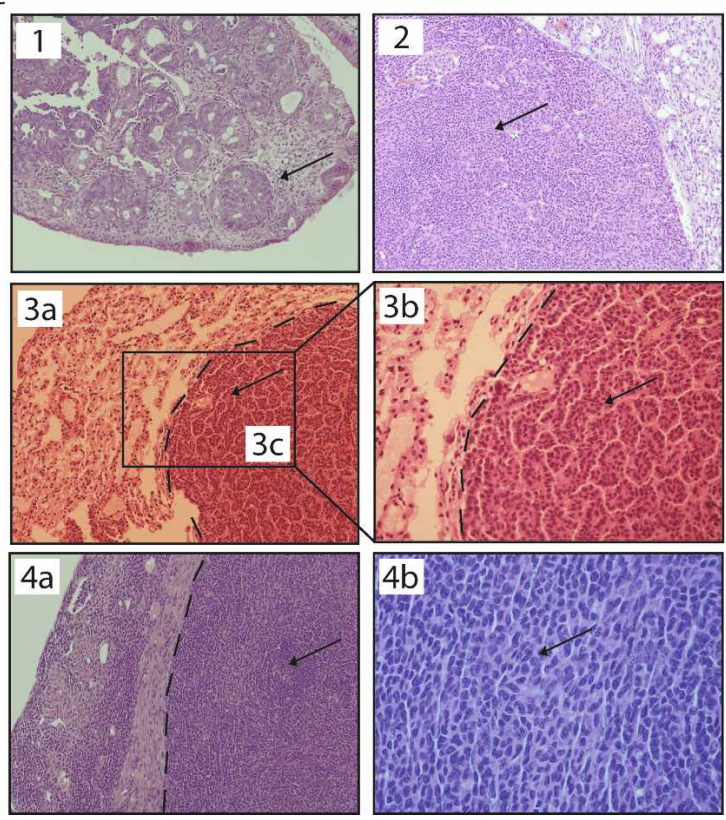

Figure 5. TAp73 $3^{-/-}$mice are tumor-prone and sensitive to carcinogens. (A) Kaplan-Meyer survival curves of TAp73 ${ }^{+/+}(n=18)$, TAp73 $3^{+-}(n=20)$, and TAp73 ${ }^{-/-}(n=22)$ mice. $P<0.001$ (Logrank test). $(B)$ Spontaneous tumor spectrum in TAp73 $3^{+/+}$, TAp73 ${ }^{+/-}$, and TAp $73^{-/-}$mice. Spontaneous tumor development in TAp73 ${ }^{-1-}$ mice is significative with a $P$-value of $P<0.005$ (X2 Test). (C, arrows) $\mathrm{H} \& E$-stained tumors in tissues of TAp73-/- mice. (1) Colon carcinoma in situ, 10x magnification. (2) Invasive lymphoma in ovary, 10x magnification. (3a-3c) Lung adenocarcinoma, 10× magnification, with $3 b$ being a higher magnification of $3 c, 20 \times$ magnification. (4a-4b) Invasive lymphoma in uterus, $10 \times$ magnification, with $4 \mathrm{~b}$ being a higher magnification of $4 \mathrm{a}, 40 \times$ magnification. Dotted lines denote the border between healthy and tumoral tissue. $(D)$ Representative $\mathrm{LOH}$ analysis of six TAp73 $3^{+/-}$tumor-bearing mice (T1-6); (T) tumor; $(\mathrm{N})$ normal tissue. (E) Kaplan-Meyer survival curves of DMBA-treated TAp73 ${ }^{+/+}(n=23)$ and TAp73 ${ }^{-/-}(n=23)$ mice in weeks after treatment. $P<0.005$ (Logrank test).

darson et al. 2001; Hardy et al. 2001). These data are also consistent with the down-regulation of p73 transcripts that occurs in the oocytes of older patients (Steuerwald et al. 2007). The p53-family members are pivotal in the control of aging, as shown for p63 (Keyes et al. 2005; Suh et al. 2006), p53 mutant (Tyner et al. 2002), or deficient mice (Ohkusu-Tsukada et al. 1999). Regarding our results, it would be of interest that TAp73 down-regula- 
A
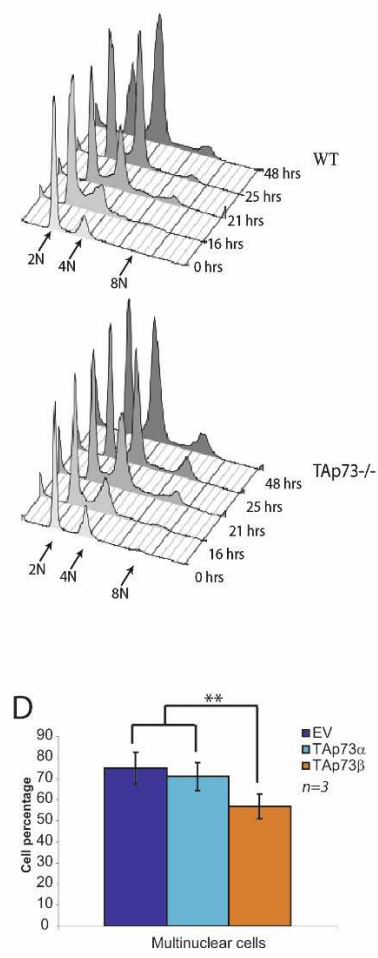

E

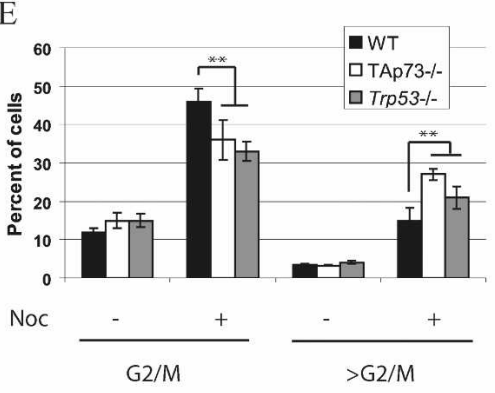

B

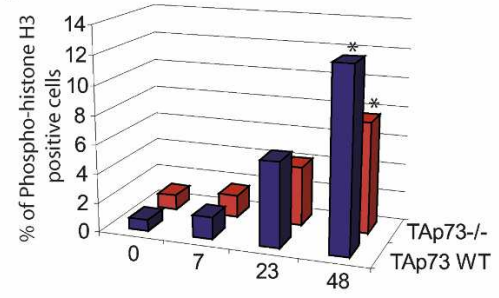

Time after treatment (hours)

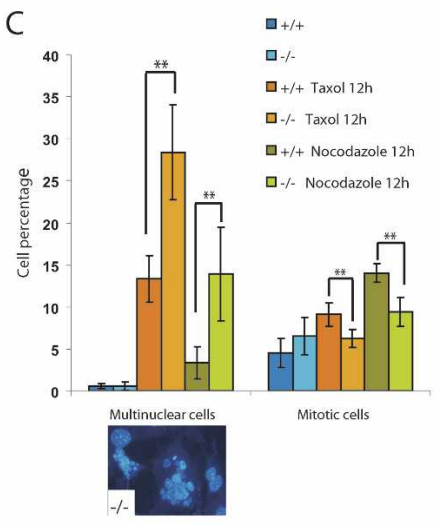

F

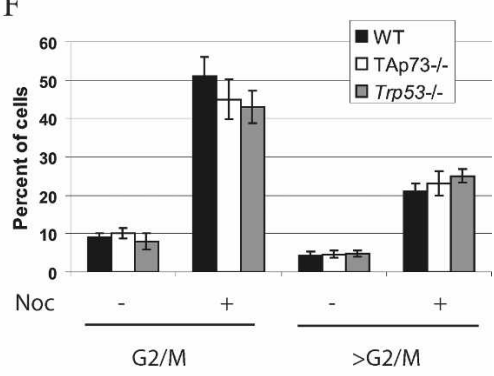

Figure 6. Defective maintenance of genomic stability in the absence of TAp73. (A) Cell cycle analysis by flow cytometry of TAp $73^{+/+}$(top) and TAp $73^{-/-}$(bottom) MEFs treated with nocodazole for the indicated number of hours. The graph was created using FlowJo 7.2.2 software. $(B)$ Percentage of phospho-histone $\mathrm{H}^{+}$cells in cultures of TAp73 $3^{+/+}$(TAp73 wild type) and TAp $73^{-/-}$MEFs treated with nocodazole for indicated times. $\left({ }^{\star}\right) P<0.01$ (Student's $t$-test). (C) Percentages of multinuclear (left) and mitotic (right) cells in TAp $73^{+/+}$and TAp73 $3^{-/-}$MEFs treated with taxol or nocodazole as indicated. (Bottom) DAPI-stained multinuclear TAp $73^{-/-}$ MEFs; 40× magnification. The data shown represent the mean \pm SE of three different experiments. $\quad\left(^{\star \star}\right) \quad P<0.001 \quad$ (Student's $t$-test). (D) Percentage of multinuclear cells in H1299 cultures overexpressing empty vector (EV) or vector containing the indicated TAp73 isoforms and treated with taxol for $\left.24 \mathrm{~h} . .^{\star \star}\right) P<0.001$ (Student's $t$-test). $(E, F)$ Percentages of cells in G2/M phase or in $>$ G2/M phase (aneuploid cells). Cells were extracted from the lung $(E)$ or thymus $(F)$ of wild-type, TAp $73^{-1-}$, and $\operatorname{Trp} 53^{-/-}$mice and treated for $12 \mathrm{~h}$ with nocodazole. The results shown are the mean percentage of cells \pm SE of three independent trials. $\left(^{\star \star}\right) \quad P<0.001$ (Student's $t$-test). (G) Increased aneuploidy. (Top) Percentages of cells in TAp $73^{+/+}$and TAp $73^{-/}$3T3 cultures showing diploid $(2 \mathrm{~N})$, near-diploid $( \pm 2 \mathrm{~N})$, tetraploid $(4 \mathrm{~N})$, near-tetraploid $( \pm 4 \mathrm{~N})$, and aneuploid $(>4 \mathrm{~N})$ DNA content. (Bottom) Representative

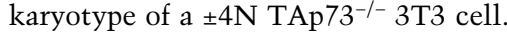

tion, due to aging or loss-of-function mutations, may be a potential prognostic factor in cases of human female infertility.

In addition to infertility, TAp $73^{-/-}$mice exhibited a mild defect in brain morphology. Hippocampal dysgenesis was observed in TAp $73^{-/-}$mice, but there were no signs of neural tissue loss or ventricular enlargement as occur in $\operatorname{Trp} 73^{-/-}$mice. Based on our studies and those of Trp73-deficient mice, we suggest that a lack of the $\Delta \mathrm{Np} 73$ isoform rather than TAp73 is responsible for neural tissue loss and ventricular enlargement in the brain, whereas hippocampal dysgenesis with loss or severe truncation of the dentate gyrus is specifically linked to TAp73 deficiency. The generation and characterization of a mouse with a selective deficiency of $\Delta \mathrm{Np} 73$ is needed to completely resolve this question.

Our study is the first clear demonstration that TAp73 isoforms possess the tumor-suppressive ability of $\operatorname{Trp} 73$, and thus resolves previous conflicting results (McKeon and Melino 2007). It has been proposed previously that a loss of p73 function might lead to tumorigenesis (Flores et al. 2002, 2005), and that TAp73 down-regulation may 
be coupled with $\Delta \mathrm{Np} 73$ up-regulation in some tumors (Zaika et al. 2002). We found that mice with a selective deficiency of TAp73 develop spontaneous tumors, particularly lung adenocarcinomas, and are more sensitive to chemical carcinogens. The development of spontaneous tumors in $\mathrm{TAp} 73^{-/-}$mice but not in $\operatorname{Trp} 73^{-/-}$mice illustrates the complex relationship between $\operatorname{Trp} 53 \mathrm{fam}$ ily members and cancer.

Intriguingly, the types of tumors detected in TAp $73^{-/-}$ mice, as well as those detected in $\operatorname{Tr} p 63^{+/-}$and $\operatorname{Tr} p 73^{+/-}$ mice, are quite different from the range of malignancies displayed by $\operatorname{Trp} 53^{-/-}$mice (even taking strain differences into account) (Flores et al. 2002, 2005). Furthermore, although p63 and p73 do not contribute to p53mediated suppression of murine lymphomagenesis in vivo (Perez-Losada et al. 2005), allelic loss and genetic instability of $\operatorname{Trp} 73$ have been linked to non-Hodgkin's lymphomas (Martinez-Delgado et al. 2002). These potentially conflicting data and the diversity in tumor spectra in these various models are likely due to the intricate pattern of expression of multiple p53, p63, and p73 isoforms. Human cancer cells can express peculiarly spliced isoforms of p 73, such as $\Delta 2 \mathrm{p} 73$ and $\Delta 2,3 \mathrm{p} 73$ (Pützer et al. 2003; Concin et al. 2004), that involve selective deletions of $\operatorname{Trp} 73$ exons 2 and 3 . These cancer cells show both elimination of the TAp73 isoform and up-regulation of a $\Delta \mathrm{Np} 73$ variant, mimicking our TAp $73^{-/-}$mice, and developing a strikingly similar phenotype. Our mouse model therefore highlights the complex interregulation of TAp73 and $\Delta \mathrm{Np} 73$ isoforms and closely reflects the aberrant pattern of p73 expression in many human cancers.

More and more evidence implicates p53 and its family members in the prevention of genomic instability, aneuploidy, and cancer, although the details of the molecular links remain unclear (Duensing and Duensing 2005). Inactivation of p53 family members may lead to a chromosomal instability phenotype that is a hallmark of cancers in which specific mitotic proteins are dysregulated (Carter et al. 2006; for review, see Tomasini et al. 2008). A recent report has shown that the combined loss of Trp73 and Trp53 induces severe genomic instability and a rapid increase in polyploidy and aneuploidy that markedly exceeds that induced by loss of Trp53 alone (Talos et al. 2007). In addition, Trp 73 seems necessary for the death of cells undergoing abnormal mitosis (Niikura et al. 2007). These results are in line with the abnormal survival described in our TAp $73^{-/-}$cells with elevated (more than 4N) DNA content. The persistence of these genetically unstable cells could then set the stage for tumorigenesis.

Our data demonstrate that TAp73 isoforms are bona fide tumor suppressors, contributing to the growing body of evidence linking genomic instability and aneuploidy with tumorigenesis (Pérez de Castro et al. 2007; Weaver and Cleveland 2007). Specifically, our findings point to a critical emerging role for the TAp73 isoform in the maintenance of genomic stability that prevents both tumor formation and infertility. Indeed, like p53 (Hu et al. 2007) and p63 (Suh et al. 2006), the entire p53 family seems to act as "the guardian of the female germline."

\section{Materials and methods}

Generation of $\mathrm{TAp} 73^{-/-}$mice and $\mathrm{LOH}$ analysis

Mutant mice deficient for Trp73 exons 2 and 3, which are specific for the TAp73 isoforms, were generated by conventional gene targeting procedures in Sv129Ola embryonic stem cells. Blastocysts were transferred to pseudopregnant C57BL/6J female mice. TAp73 wild-type (wild type, +/+; TAp $73^{+/+}$), heterozygous (+/-; TAp73 $\left.{ }^{+-}\right)$, and homozygous $\left(-/-\right.$; TAp $\left.73^{-/-}\right)$littermate mice (Sv129Ola $\times$ C57BL/6J) were created by intercrossing TAp $73^{+/-}$mice. Offspring were genotyped by PCR analysis using specific primer pairs to detect the wild-type $\operatorname{Trp} 73$ and $\operatorname{Trp} 73^{\Delta T A}$ alleles. Sense and antisense primers for the wild-type $\operatorname{Trp} 73$ allele were 5'-CTGGTCCAGGAGGTGAGACTGAG GC-3' and 5'-CTGGCCCTCTCAGCTTGTGCCACTTC-3', respectively. Sense and antisense primers for the gene-targeted $\operatorname{Trp} 73^{\Delta T A}$ allele were $5^{\prime}$-GTGGGGGTGGGATTAGATAAAT GCCTG-3' and 5'-CTGGCCCTCTCAGCTTGTGCCACTTC$3^{\prime}$, respectively. Predicted PCR product sizes were $1.0 \mathrm{~kb}$ and 1.2 kb for the wild-type $\operatorname{Trp} 73$ and $\operatorname{Tr} p 73^{\Delta T A}$ alleles, respectively. F4 mixed background mice were used for all experiments except the analysis of the Mendelian ratio, for which we also used animals of the fifth-generation backcross in a C57B6 background. All animals were treated in accordance with the NIH Guide for Care and Use of Laboratory Animals as approved by the Ontario Cancer Institute Animal Care Committee (Toronto, ON, Canada). LOH analysis was performed using genotyping primers and PCR amplification of Trp73 exons 2 and 3 in genomic DNA from tumor and normal (tail) tissues of tumor-bearing TAp $73^{+/-}$mice.

Analyses of spontaneous and induced tumors

Life span and spontaneous tumor incidence were determined in untreated TAp $73^{+/+}$and TAp $73^{-/-}$mice. Mice with visible tumors and moribund mice showing weight loss or difficulties in moving were sacrificed upon detection. The remaining surviving mice were sacrificed at 26 mo of age. For induced tumorigenesis, $\mathrm{TAp} 73^{+/+}$and TAp $73^{-/-}$mice $(23$ mice/group) were injected i.p. with $1 \mathrm{mg} / \mathrm{kg}$ dimethylbenz[a]anthracene (DMBA; Sigma-Aldrich) starting at $63 \mathrm{~d}$ post-partum and continuing once a week for $6 \mathrm{wk}$. This dose was sufficient to induce $100 \%$ tumor incidence in controls. Tumors and tissues of control and mutant mice were collected and processed for histopathology and RNA/DNA isolation by standard procedures.

\section{Oocyte collection, in vitro maturation, and in vitro fertilization}

Female mice (3-7 wk old) were superovulated, and mature oocytes were collected as previously described (Perez et al. 2005). For in vitro maturation, germinal vesicle stage oocytes from 3 -wk-old females were induced to undergo spontaneous in vitro maturation (Yao et al. 2004), and in vitro fertilization was carried out as described previously (Acton et al. 2004). Embryonic developmental competence was assessed daily. On day 4, embryos were fixed and cell number, cell death, and mitotic rates were determined as described previously (Jurisicova et al. 1998). Statistics were obtained using the $\chi^{2}$ or Student's $t$-test.

\section{Microarray studies}

Microarray analysis was performed on day 4 ovarian tissue from two sibling pairs of TAp $73^{+/+}$and TAp $73^{-/-}$females by the Cen- 
ter for Applied Genomics (Hospital for Sick Children, Toronto) using the Affymetrix platform (Mouse MOE 430 2.0) with two cycle amplification steps. Data were preprocessed using RMAExpress 1.0 beta 3 (Bolstad et al. 2003), $\log _{2}$ transformed, and then analyzed using SAM version 3.0 (Tusher et al. 2001). Using FDR (False Discovery Rate) $=0.603 \%$, we identified 2538 genes that were differentially expressed (1178 up-regulated and 1360 down-regulated in TAp $73^{+/+}$ovaries). To further diminish false positives, we prioritized the genes by considering only fold change $>1.8$, which resulted in 16 genes up-regulated and 60 genes down-regulated in wild-type ovaries.

To determine functional links among identified target genes, we mapped them to the Interologous Interaction Database $\mathrm{I}^{2} \mathrm{D}$ ver. 1.71 (http://ophid.utoronto.ca/i2d). A network was formed containing 531 proteins and 977 interactions on seven targets up-regulated in TAp $73^{+/+}$ovaries and 26 targets up-regulated in TAp $73^{-/-}$ovaries. Further visualization and analysis of the resulting protein interaction network were performed using NAViGaTOR ver 2.0 (http://ophid.utoronto.ca/navigator). Shortest path calculations were used to determine critical proteins and interactions. Briefly, the shortest path among all nodes within the network was computed, and the frequency of inclusion of individual proteins and interactions was counted. The most frequent nodes and lines form the critical subgraph within the network. We applied blending to reduce network complexity (NAViGaTOR version 2.0).

\section{Immunohistochemical analysis}

For histological analysis of mouse brains, sacrificed animals were perfused with $4 \%$ paraformaldehyde, and their brains were cryoprotected, sectioned, and Nissl-stained as described previously (Pozniak et al. 2002). For histological analysis of oocytes, oocyte fixation and immunocytochemistry were performed as described previously (Yao et al. 2004). Samples were viewed on a deconvolution fluorescence microscope. Follicular histomorphology was performed on fixed ovarian tissue obtained from 3-wk-old females (Canning et al. 2003), and immunocytochemistry on ovarian sections was performed as described previously (Matikainen et al. 2001). The antibodies used for analyses of oocytes and/or ovarian sections were rat monoclonal anti-tubulin (YL1/2; Abcam), rabbit polyclonal anti-p73 (H79; Santa Cruz Biotechnologies), and goat anti-p $73 \alpha$ (C17; Santa Cruz Biotechnologies). For spindle analyses, secondary antibody was conjugated to Oregon green (Molecular Probes). For ovarian sections, visualization was performed using a biotinylated anti-rabbit antibody detection kit (DAKO).

\section{Cell lines and overexpression experiments}

MEFs obtained from embryonic day 13.5 (E13.5) $\mathrm{TAp}^{+/+}$, TAp $73^{-/-}$, and $\mathrm{p} 73^{-/-}$embryos, or $3 \mathrm{~T} 3$ cells, were cultured in Dulbecco's modified Eagle's medium (DMEM) supplemented with $10 \%$ FCS without antibiotics. For overexpression experiments, the human lung carcinoma cell line H1299 was plated at $60 \%$ density the day before transfections. Transient transfection of plasmids was carried out using the FuGENE reagent (Roche Applied Science) according to the manufacturer's protocol. Control vector pcDNA3-HA was from Clontech. DNA sequences encoding the TAp73 $\alpha$ and TAp73 $\beta$ isoforms were all cloned in pcDNA3-HA.

\section{Flow cytometric analyses}

TAp $73^{-/-}$MEFs were seeded at $3 \times 10^{5}$ cells per $100-\mathrm{mm}$ plate. Cultures were then either left untreated or treated with noco- dazole (200 ng/mL; Sigma-Aldrich). Immediately (control) or at $16,21,25$, or $48 \mathrm{~h}$ after nocodazole treatment, cells were harvested and fixed for at least $1 \mathrm{~h}$ at $4^{\circ} \mathrm{C}$ in $\mathrm{PBS} / 70 \%$ ethanol. Fixed cells were resuspended in PBS containing $100 \mu \mathrm{g} / \mathrm{mL}$ RNase A and $50 \mu \mathrm{g} / \mathrm{mL}$ propidium iodide (Sigma-Aldrich) and immediately analyzed using a FACSCalibur (Becton Dickinson Biosciences). Data were collected and analyzed with CellQuest Pro (BD Biosciences) and FlowJo 7.2.2 Data Analysis Software. Phospho-histone H3 staining was performed using an anti-phospho-histone H3 antibody (\#9708; Cell Signaling) according to the manufacturer's protocol. Cell cycle analysis of total cell populations from fresh TAp $73^{+/+}, \mathrm{TAp} 73^{-/-}$, and $\mathrm{p} 53^{-/-}$thymus or lung tissues was performed as previously described (Yamamoto et al. 2003).

Cell death analysis was performed by flow cytometry using propidium iodide staining together with AnnexinV-FITC as described previously.

\section{Western blotting}

Protein extracts $(100 \mu \mathrm{g})$ were fractionated by SDS-PAGE and subjected to Western blotting by standard procedures. Western blots were quantified by band densitometry using an Odyssey Infrared Imaging System (LI-COR Biosciences). For immunoprecipitations, protein extracts from MEFs were analyzed according to standard protocols. The antibodies used for Western blot were mouse anti- $\Delta$ Np73 (IMG-313; Imgenex), goat anti-p73 (C20; Santa Cruz), rabbit anti-phospho-p53 ser15 (\#9284L; Cell Signaling), and rabbit anti-p53 total (CM5; Vector Laboratories).

\section{Acknowledgments}

We gratefully acknowledge H. Okada and R.A. Knight for technical advice and helpful discussions, P. Berthezene for statistical analysis, S.K. Lau for technical help with human real-time PCR analysis, and M.E. Saunders for scientific editing. This work was supported by grants from AIRC, EU (Active-p53, Epistem), FIRB, MIUR, and MinSan to G.M. R.T. was supported by l'Association pour la recherche contre le cancer. R.T, K.T., and A.J. were supported by the Canadian Institutes of Health Research. R.T., K.T., M.W., M.F., A.R., C.C.C., F.K., A.I.-Y., A.W., P.B., and A.J. conducted research for the paper. R.T., G.M., A.J., and T.W.M. wrote the paper. We all discussed the results and read the paper.

\section{References}

Acton, B.M., Jurisicova, A., Jurisica, I., and Casper, R.F. 2004. Alterations in mitochondrial membrane potential during preimplantation stages of mouse and human embryo development. Mol. Hum. Reprod. 10: 23-32.

Akanuma, T., Koshida, S., Kawamura, A., Kishimoto, Y., and Takada, S. 2007. Pafl complex homologues are required for Notch-regulated transcription during somite segmentation. EMBO Rep. 8: 858-863.

Baird, D.T., Collins, J., Egozcue, J., Evers, L.H., Gianaroli, L., Leridon, H., Sunde, A., Templeton, A., Van Steirteghem, A., Cohen, J., et al. 2005. Fertility and ageing. Hum. Reprod. Update 11: 261-276.

Bolstad, B.M., Irizarry, R.A., Astrand, M., and Speed, T.P. 2003. A comparison of normalization methods for high density oligonucleotide array data based on bias and variance. Bioinformatics 19: 185-193.

Bourdon, J.C., Fernandez, K., Murray-Zmijewski, K., Liu, G., Diot, A., Xirodimas, D.P., Saville, M.K., and Lane, D.P. 2005. 
p53 isoforms can regulate p53 transcriptional activity. Genes \& Dev. 19: 2122-2137.

Brown, K. and Jurisica, I. 2007. Unequal evolutionary conservation of human protein interactions in interologous networks. Genome Biol. 8: R95. doi: 10.1186/gb-2007-8-5-r95.

Canning, J., Takai, Y., and Tilly, J.L. 2003. Evidence for genetic modifiers of ovarian follicular endowment and development from studies of five inbred mouse strains. Endocrinology 144: $9-12$.

Carter, S.L., Eklund, A.C., Kohane, I.S., Harris, L.N., and Szallasi, Z. 2006. A signature of chromosomal instability inferred from gene expression profiles predicts clinical outcome in multiple human cancers. Nat. Genet. 38: $1043-1048$.

Coates, P.J. 2006. Regulating p73 isoforms in human tumours. J. Pathol. 210: 385-389.

Concin, N., Becker, K., Slade, N., Erster, S., Mueller-Holzner, E., Ulmer, H., Daxenbichler, G., Zeimet, A., Zeillinger, R., Marth, C., et al. 2004. Transdominant $\Delta$ TAp73 isoforms are frequently up-regulated in ovarian cancer. Evidence for their role as epigenetic p53 inhibitors in vivo. Cancer Res. 64: 2449-2460.

De Laurenzi, V., Costanzo, A., Barcaroli, D., Terrinoni, A., Falco, M., Annicchiarico-Petruzzelli, M., Levrero, M., and Melino, G. 1998. Two new p73 splice variants, $\gamma$ and $\delta$, with different transcriptional activity. J. Exp. Med. 188: 1763-1768.

Deyoung, M.P. and Ellisen, L.W. 2007. p63 and p73 in human cancer: Defining the network. Oncogene 26: 5169-5183.

Donehower, L.A., Harvey, M., Slagle, B.L., McArthur, M.J., Montgomery Jr., C.A., Butel, J.S., and Bradley, A. 1992. Mice deficient for p53 are developmentally normal but susceptible to spontaneous tumours. Nature 356: 215-221.

Duensing, A. and Duensing, S. 2005. Guilt by association? p53 and the development of aneuploidy in cancer. Biochem. Biophys. Res. Commun. 331: 694-700.

Erster, S., Palacios, G., Rosenquist, T., Chang, C., and Moll, U.M. 2006. Deregulated expression of $\Delta \mathrm{Np} 73 \alpha$ causes early embryonic lethality. Cell Death Differ. 13: 170-173.

Flores, E.R., Tsai, K.Y., Crowley, D., Sengupta, S., Yang, A., McKeon, F., and Jacks, T. 2002. p63 and p73 are required for p53-dependent apoptosis in response to DNA damage. $\mathrm{Na}$ ture 416: 560-564.

Flores, E.R., Sengupta, S., Miller, J.B., Newman, J.J., Bronson, R., Crowley, D., Yang, A., McKeon, F., and Jacks, T. 2005. Tumor predisposition in mice mutant for p63 and p73: Evidence for broader tumor suppressor functions for the p53 family. Cancer Cell 7: 363-373.

Grob, T.J., Novak, U., Maisse, C., Barcaroli, D., Lüthi, A.U., Pirnia, F., Hügli, B., Graber, H.U., De Laurenzi, V., Fey, M.F., et al. 2001. Human $\Delta \mathrm{Np} 73$ regulates a dominant negative feedback loop for TAp73 and p53. Cell Death Differ. 8: 12131223.

Hardarson, T., Hanson, C., Sjogren, A., and Lundin, K. 2001. Human embryos with unevenly sized blastomeres have lower pregnancy and implantation rates: Indications for aneuploidy and multinucleation. Hum. Reprod. 16: 313-318.

Hardy, K., Spanos, S., Becker, D., Iannelli, P., Winston, R.M., and Stark, J. 2001. From cell death to embryo arrest: Mathematical models of human preimplantation embryo development. Proc. Natl. Acad. Sci. 98: 1655-1660.

Haruki, N., Harano, T., Masuda, A., Kiyono, T., Takahashi, T., Tatematsu, Y., Shimuzu, S., Mitsudomi, T., Konishi, H., Osada, H., et al. 2001. Persistent increase in chromosome instability in lung cancer: Possible indirect involvement of p53 inactivation. Am. J. Pathol. 159: 1345-1352.
Hassold, T. and Hunt, P. 2001. To err (meiotically) is human: The genesis of human aneuploidy. Nat. Rev. Genet. 2: 280291.

Hu, W., Feng, Z., Teresky, A.K., and Levine, A.J. 2007. p53 regulates maternal reproduction through LIF. Nature 450: 721724.

Huttinger-Kirchhof, N., Cam, H., Griesmann, H., Hofmann, L., Beitzinger, M., and Stiewe, T. 2006. The p53 family inhibitor $\Delta \mathrm{Np} 73$ interferes with multiple developmental programs. Cell Death Differ. 13: 174-177.

Irwin, M., Marin, M.C., Phillips, A.C., Seelan, R.S., Smith, D.I., Liu, W., Flores, E.R., Tsai, K.Y., Jacks, T., Vousden, K.H., et al. 2000. Role for the p53 homologue p73 in E2F-1-induced apoptosis. Nature 407: 645-648.

Jurisicova, A., Rogers, I., Fasciani, A., Casper, R.F., and Varmuza, S. 1998. Effect of maternal age and conditions of fertilization on programmed cell death during murine preimplantation embryo development. Mol. Hum. Reprod. 4: 139145.

Kaghad, M., Bonnet, H., Yang, A., Creancier, L., Biscan, J.C., Valent, A., Minty, A., Chalon, P., Lelias, J.M., Dumont, X., et al. 1997. Monoallelically expressed gene related to p53 at $1 \mathrm{p} 36$, a region frequently deleted in neuroblastoma and other human cancers. Cell 90: 809-819.

Keyes, W.M., Wu, Y., Vogel, H., Guo, X., Lowe, S.W., and Mills, A.A. 2005. p63 deficiency activates a program of cellular senescence and leads to accelerated aging. Genes \& Dev. 19: 1986-1999.

Klanrit, P., Flinterman, M.B., Odell, E.W., Melino, G., Killick, R., Norris, J.S., and Tavassoli, M. 2008. Specific isoforms of p73 control the induction of cell death induced by the viral proteins, E1A or apoptin. Cell Cycle 7: 207-215.

Li, Y. and Prives, C. 2007. Are interactions with p63 and p73 involved in mutant p53 gain of oncogenic function? Oncogene 26: 2220-2225.

Lissy, N.A., Davis, P.K., Irwin, M., Kaelin, W.G., and Dowdy, S.F. 2000. A common E2F-1 and p73 pathway mediates cell death induced by TCR activation. Nature 5: 642-645.

Maisse, C., Munarriz, E., Barcaroli, D., Melino, G., and De Laurenzi, V. 2004. DNA damage induces the rapid and selective degradation of the $\Delta \mathrm{Np} 73$ isoform, allowing apoptosis to occur. Cell Death Differ. 11: 685-687.

Martinez-Delgado, B., Melendez, B., Cuadros, M., Garcia, M.J., Nomdedeu, J., Rivas, C., Fernandez-Piqueras, J., and Benitez, J. 2002. Frequent inactivation of the p73 gene by abnormal methylation or LOH in non-Hodgkin's lymphomas. Int. J. Cancer 102: 15-19.

Matikainen, T., Perez, G.I., Jurisicova, A., Pru, J.K., Schlezinger, J.J., Ryu, H.-Y., Laine, J., Sakai, T., Korsmeyer, S.J., Casper, R.F., et al. 2001. Aromatic hydrocarbon receptor-driven Bax gene expression is required for premature ovarian failure caused by biohazardous environmental chemicals. Nat. Genet. 28: 355-360.

McKeon, F. and Melino, G. 2007. Fog of war: The emerging p53 family. Cell Cycle 6: 229-232.

Mills, A.A., Zheng, B., Wang, X.J., Vogel, H., Roop, D.R., and Bradley, A. 1999. p63 is a p53 homologue required for limb and epidermal morphogenesis. Nature 398: 708-713.

Müller, M., Schilling, T., Sayan, A.E., Kairat, A., Lorenz, K., Schulze-Bergkamen, H., Oren, M., Koch, A., Tannapfel, A., and Stremmel, W. 2005. TAp73/ $\Delta$ Np73 influences apoptotic response, chemosensitivity and prognosis in hepatocellular carcinoma. Cell Death Differ. 12: 1564-1577.

Munarriz, E., Barcaroli, D., Stephanou, A., Townsend, P.A., Maisse, C., Terrinoni, A., Neale, M.H., Martin, S.J., Latchman, D.S., Knight, R.A., et al. 2004. PIAS-1 is a checkpoint 
regulator which affects exit from G1 and G2 by sumoylation of p73. Mol. Cell. Biol. 24: 10593-10610.

Murray-Zmijewski, F., Lane, D.P., and Bourdon, J.C. 2006. p53/ p63/p73 isoforms: An orchestra of isoforms to harmonise cell differentiation and response to stress. Cell Death Differ. 13: 962-972.

Niikura, Y., Dixit, A., Scott, R., Perkins, G., and Kitagawa, K. 2007. BUB1 mediation of caspase-independent mitotic death determines cell fate. J. Cell Biol. 178: 283-296.

Ohkusu-Tsukada, K., Tsukada, T., and Isobe, K. 1999. Accelerated development and aging of the immune system in p53deficient mice. J. Immunol. 163: 1966-1972.

Ono, R., Nakamura, K., Inoue, K., Naruse, M., Usami, T., Wakisaka-Saito, N., Hino, T., Suzuki-Migishima, R., Ogonuki, N., Miki, H., et al. 2006. Deletion of Peg10, an imprinted gene acquired from a retrotransposon, causes early embryonic lethality. Nat. Genet. 38: 101-106.

Perez, G.I., Jurisicova, A., Matikainen, T., Moriyama, T., Kim, M., Takai, Y., Pru, J.K., Kolesnick, R.N., and Tilly, J.L. 2005. A central role for ceramide in the aging-related acceleration of apoptosis in the female germ line. FASEB J. 19: 860-872.

Pérez de Castro, I., de Cárcer, G., and Malumbres, M. 2007. A census of mitotic cancer genes: New insights into tumor cell biology and cancer therapy. Carcinogenesis 28: 899-912.

Perez-Losada, J., Wu, D., Delrosario, R., Balmain, A., and Mao, J.H. 2005. p63 and p73 do not contribute to p53-mediated lymphoma suppressor activity in vivo. Oncogene 24: 55215524.

Pozniak, C.D., Radinovic, S., Yang, A., McKeon, F., Kaplan, D.R., and Miller, F.D. 2000. An anti-apoptotic role for the p53 family member, p73, during developmental neuron death. Science 289: 304-306.

Pozniak, C.D., Barnabe-Heider, F., Rymar, V.V., Lee, A.F., Sadikot, A.F., and Miller, F.D. 2002. p73 is required for survival and maintenance of CNS neurons. J. Neurosci. 22: 98009809.

Pützer, B.M., Tuve, S., Tannapfel, A., and Stiewe, T. 2003. Increased $\Delta \mathrm{N}-\mathrm{p} 73$ expression in tumors by upregulation of the E2F1-regulated, TA-promoter-derived $\Delta \mathrm{N}^{\prime}$-p73 transcript. Cell Death Differ. 10: 612-614.

Roman-Gomez, J., Gimenez-Velasco, A., Agirre, X., Castillejo, J.A., Navarro, G., Calasanz, M.J., Garate, L., San jose-Eneriz, E., Cordeu, L., Prosper, F., et al. 2006. CpG island methylator phenotype redefines the prognostic effect of $\mathrm{t}(12 ; 21)$ in childhood acute lymphoblastic leukemia. Clin. Cancer Res. 12: 4845-4850.

Steuerwald, N.M., Bermúdez, M.G., Wells, D., Munné, S., and Cohen, J. 2007. Maternal age-related differential global expression profiles observed in human oocytes. Reprod. Biomed. Online 14: 700-708.

Stiewe, T. 2007. The p53 family in differentiation and tumorigenesis. Nat. Rev. Cancer 7: 165-168.

Stiewe, T. and Pützer, B.M. 2000. Role of the p53-homologue p73 in E2F1-induced apoptosis. Nat. Genet. 26: 464-469.

Suh, E.K., Yang, A., Kettenbach, A., Bamberger, C., Michaelis, A.H., Zhu, Z., Elvin, J.A., Bronson, R.T., Crum, C.P., and McKeon, F. 2006. p63 protects the female germ line during meiotic arrest. Nature 444: 624-628.

Talos, F., Nemajerova, A., Flores, E.R., Petrenko, O., and Moll, U.M. 2007. p73 suppresses polyploidy and aneuploidy in the absence of functional p53. Mol. Cell 27: 647-659.

Tarin, J.J., Perez-Albala, S., and Cano, A. 2001. Cellular and morphological traits of oocytes retrieved from aging mice after exogenous ovarian stimulation. Biol. Reprod. 65: 141150.

Thomas, N.S., Ennis, S., Sharp, A.J., Durkie, M., Hassold, T.J.,
Collins, A.R., and Jacobs, P.A. 2001. Maternal sex chromosome non-disjunction: Evidence for X chromosome-specific risk factors. Hum. Mol. Genet. 10: 243-250.

Toh, W.H., Siddique, M.M., Boominathan, L., Lin, K.W., and Sabapathy, K. 2004. c-Jun regulates the stability and activity of the p53 homologue, p73. J. Biol. Chem. 279: 44713-44722.

Tomasini, R., Mak, T.W., and Melino, G. 2008. The impact of p53 and p73 on aneuploidy and cancer. Trends Cell Biol. 18: 244-252.

Tusher, V.G., Tibshirani, R., and Chu, G. 2001. Significance analysis of microarrays applied to the ionizing radiation response. Proc. Nat1. Acad. Sci. 98: 5116-5121.

Tyner, S.D., Ventakachalam, S., Choi, J., Jones, S., Ghebranious, N., Igelmann, H., Lu, X., Soron, G., Cooper, B., Brayton, C., et al. 2002. p53 mutant mice that display early ageing-associated phenotypes. Nature 415: 45-53.

Vousden, K.H. and Lane, D.P. 2007. p53 in health and disease. Nat. Rev. Mol. Cell Biol. 8: 275-283.

Walsh, G.S., Orike, N., Kaplan, D.R., and Miller, F.D. 2004. The invulnerability of adult neurons: A critical role for $\mathrm{p} 73 . J$. Neurosci. 24: 9638-9647.

Wang, J., Liu, Y.X., Hande, M.P., Wong, A.C., Jin, Y.J., and Yin, Y. 2007. TAp73 is a downstream target of p53 in controlling the cellular defense against stress. J. Biol. Chem. 282: 2915229162.

Weaver, B.A. and Cleveland, D.W. 2007. Aneuploidy: Instigator and inhibitor of tumorigenesis. Cancer Res. 67: 10103-10105.

Yamamoto, M., Sato, S., Hemmi, H., Uematsu, S., Hoshino, K., Kaisho, T., Takuechi, O., Takeda, K., and Akira, S. 2003. TRAM is specifically involved in the toll-like receptor 4-mediated MyD88-independent signaling pathway. Nat. Immunol. 4: 1144-1150.

Yang, A., Schweitzer, R., Sun, D., Kaghad, M., Walker, N., Bronson, R.T., Tabin, C., Sharpe, A., Caput, D., and Crum, C. 1999. p63 is essential for regenerative proliferation in limb, craniofacial and epithelial development. Nature 398: 714718 .

Yang, A., Walker, N., Bronson, N., Kaghad, M., Oosterwegel, M., Bonnin, J., Vagner, C., Bonnet, H., Dikkes, P., Sharpe, A., et al. 2000. p73-deficient mice have neurological, pheromonal and inflammatory defects but lack spontaneous tumours. Nature 404: 99-103.

Yang, A., Kaghad, M., Caput, D., and McKeon, F. 2002. On the shoulders of giants: p63, p73 and the rise of p53. Trends Genet. 18: 90-95.

Yao, L.J., Zhong, Z.S., Zhang, L.S., Chen, D.Y., Schatten, H., and Sun, Q.Y. 2004. Aurora-A is a critical regulator of microtubule assembly and nuclear activity in mouse oocytes, fertilized eggs, and early embryos. Biol. Reprod. 70: 1392-1399.

Yuen, K.W., Montpetit, B., and Hieter, P. 2005. The kinetochore and cancer: What's the connection? Curr. Opin. Cell Biol. 17: 576-582.

Zaika, A.I., Slade, N., Erster, S.H., Sansome, C., Joseph, T.W., Pearl, M., Chalas, E., and Moll, U.M. 2002. $\Delta$ Np73, a dominant-negative inhibitor of wild-type p53 and TAp73, is upregulated in human tumors. J. Exp. Med. 196: 765-780. 


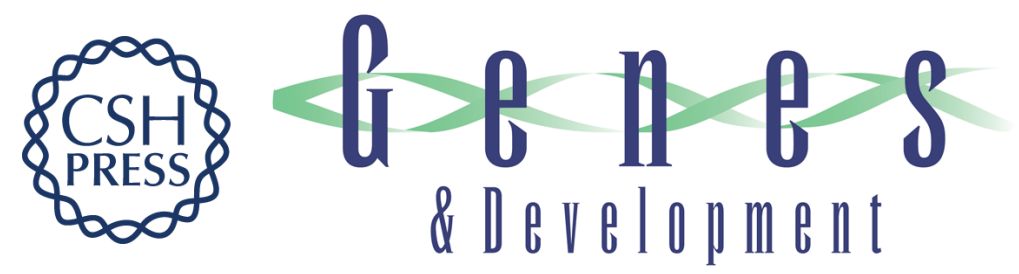

\section{TAp73 knockout shows genomic instability with infertility and tumor suppressor functions}

Richard Tomasini, Katsuya Tsuchihara, Margareta Wilhelm, et al.

Genes Dev. 2008, 22: originally published online September 19, 2008

Access the most recent version at doi:10.1101/gad.1695308

\section{Supplemental http://genesdev.cshlp.org/content/suppl/2008/09/19/gad.1695308.DC1 \\ Material}

Related Content The jury is in: $\mathrm{p73}$ is a tumor suppressor after all Jennifer M. Rosenbluth and Jennifer A. Pietenpol

Genes Dev. October , 2008 22: 2591-2595

References This article cites 71 articles, 17 of which can be accessed free at: http://genesdev.cshlp.org/content/22/19/2677.full.html\#ref-list-1

Articles cited in:

http://genesdev.cshlp.org/content/22/19/2677.full.html\#related-urls

License Freely available online through the Genes \& Development Open Access option.

Email Alerting Receive free email alerts when new articles cite this article - sign up in the box at the top Service right corner of the article or click here.

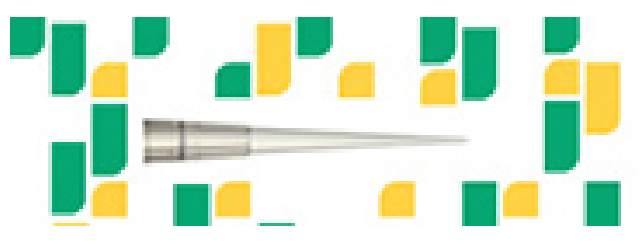

Focused on your science. 